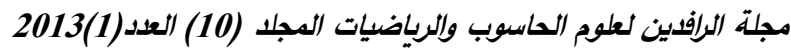 عدد خاص بوقائع الدؤتمد العلمي الخامس في تقانة الدعلومات 19-20 كانون الأول 2012
}

\section{Design a Tool for Generating Test Cases using Swarm Intelligence}

\author{
Shahbaa I. Khaleel \\ shahbaaibrkh@uomosul.edu.iq \\ College of Computer Sciences and Mathematics \\ Ashraf Abdulmunim Al Thanoon \\ University of Mosul, Mosul, Iraq
}

Received on: 24/10/2012

\begin{abstract}
In this research, the tools and techniques of artificial intelligence were studied and employed in software engineering. And that was conducted through using the Particle Swarm Optimization PSO and Cat Swarm Optimization CSO in generating optimal test cases of the software written with $\mathrm{C}++$ language in an automatic way because that enables the corporation which develops the program to save time and costs as well as ensuring the test process quality, which is estimated by $50 \%$ of the product cost. In this research, the software engineering tool Generate Test Suite GTS TOOL was constructed and modeled with the aid of the computer, which is used to generate optimal test cases automatically and this tool also support the drawing of the control flowgraphs and paths inside the program and tests each path using CSO and PSO. The proposed tool succeeded in generating optimal test cases for several programs and in a very short time. The average of generating the test cases using PSO was 4 minutes and 1.2 minutes for CSO. Where the performance of the CSO was much better than the performance of PSO.
\end{abstract}

Keywords: Particle Swarm Optimization PSO, Cat Swarm Optimization CSO, control flowgraphs, test cases.

$$
\begin{aligned}
& \text { تصميم أداة لتوليد حالات الاختبار باعتماد ذكاء السرب }
\end{aligned}
$$

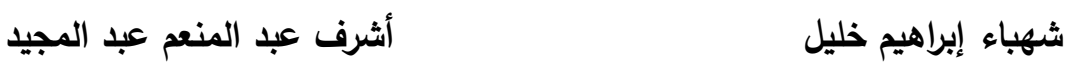

$$
\begin{aligned}
& \text { كلية علوم الحاسوب واليراضيات } \\
& \text { جامعة الدوصل، الدوصل، العراق }
\end{aligned}
$$

تاريخ قبول البحث: 2013/01/30

تاريخ استلام البحث: 2012/10/24

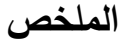

في هذا البحث تمت دراسة آليات الذكاء الاصطناعي وتقنياتها بغية توظيفها في خدمة هندسة البرمجيات، وقد أنجز ذلك من خلال استخدام خوارزمية سرب الطيور Particle swarm optimization PSO وخوارزمية سرب القطط عل في توليد حالات الاختبار المثالية للبرمجيات المكتوبة بلغة C++ وبشكل تلقائي مما سيوفر للمؤسسة المطورة للبرمجيات الوقت والكلفة فضلاً عن ضمان جودة عملية الاختبار التي تقدر عادة بنحو 50\% من كلفة إنتاج المنتج. وقد تم في هذا البحث نمذجة أداة هندسة البرمجيات بمساعدة الحاسوب Generate Test Suite GTS TOOL وبناؤها التي تستخدم في توليد حالات اختبار مثالية بشكل تلقائي وتدعم هذه الأداة أيضاً رسم مخطط تدفق السيطرة والمسارات داخل البرنامج فضلاً عن حالة الاختبار لكل
\end{abstract}


مسار باستخدام، PSO وCSO. وقد نجحت الأداة المقترحة في توليد حالات اختبار مثالية لعدة برامج وبوقت قصير جداً، إذ كان معدل توليد حالات الاختبار باستخدام 4 PSO دقائق والـ 1.2 CSO دقيقة، حيث كان الات أداء

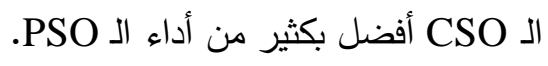
الكلمات المفتاحية : أمثلية سرب الطيور، أمثلية سرب القطط، مخطط تدفق السيطرة، حالات الاختبار.

1- المقدمة

أصبحت البرمجيات في العصر الحالي واسعة الانتشار وموجودة في كل مكان، ويتطلب هذا الوجود أو

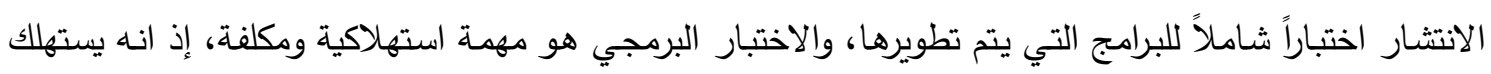

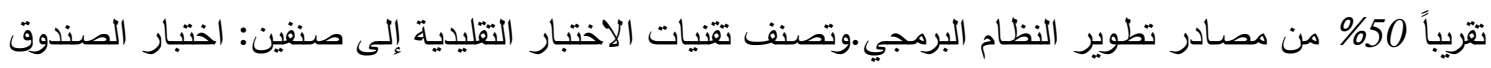

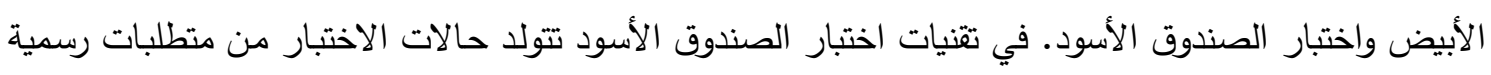

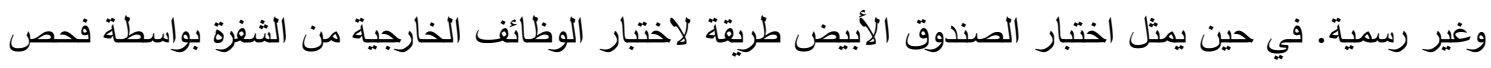
واختبار الثفرة التي تحقق الوظيفة الخارجية [2]. ويمكن للاختبار أن يحصل يدويا أو أوتوماتيكيا باستخدام أدوات لاتئل

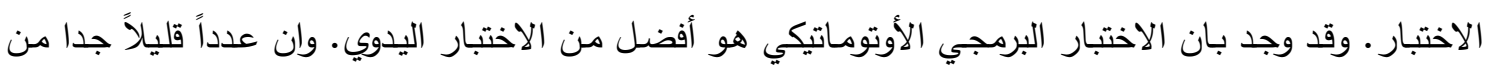

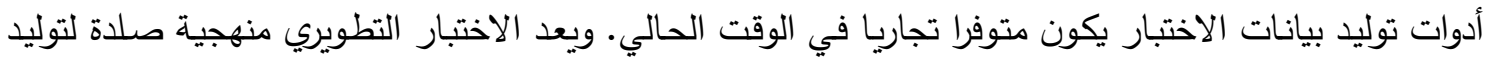

بيانات اختبار بجودة عالية وبشكل أوتوماتيكي [2]. يوضح الثكل (1) الأنموذج العام لعملية الاختبار [1].

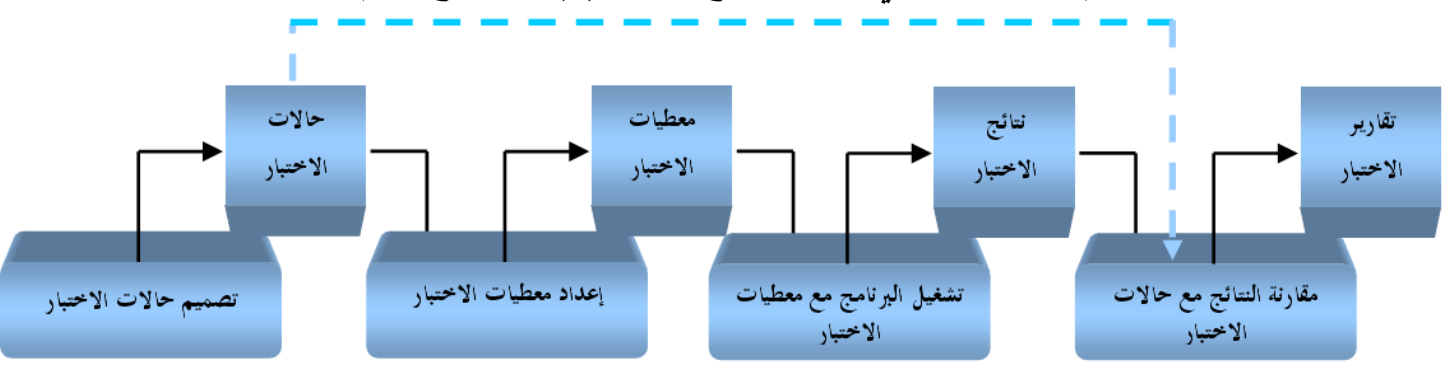

الثكل (1). الأنموذج العام لعملية الاختبار

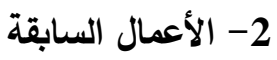

في عام 2000 قدم الباحثان Nguyen Tran Sy, Yves Deville طريقة جديدة لتوليد بيانات الاختبار

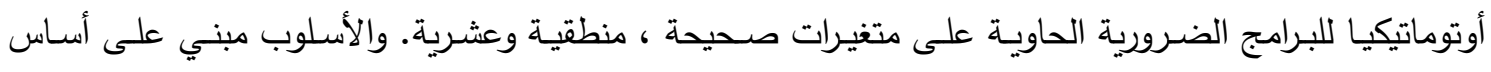
تقنيات التماسك consistency techniques التي تدمج متغيرات صحيحة وعشرية[5]. قام الباحثون كل من Joachim Wegener, Stefan Wappler, Andreas Windisch software في اختبار البرمجيات Abdelaziz M. Khamis , Moheb R . testing عام 2007 تدمج بين مفهوم مجاميع الامتداد Girgis , Ahmed S. G hiduk

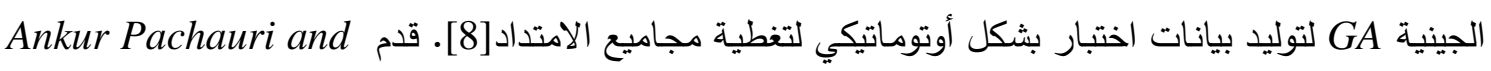
Gursaran مع صيغة النقصان minimization formulation وتم استخدام GA و الاعتيادية[10] مع ملعه 
3- 3- الدوافع لإجراء عملية الاختبار

يمكن تحسين أداء العمليات عن طريق فهم واستيعاب الأسباب الجذرية لحدوث الخلل والأخطاء المكتشفة

في المشاريع وهذا بدوره يجب أن يمنع تكرار حدوث الخلل وبالتالي تحسين جودة الأنظمة المستقبلية [3]. الاختبار الفعال قبل نشر المنتج يحقق ثلاثة منافع رئيسة وهي:

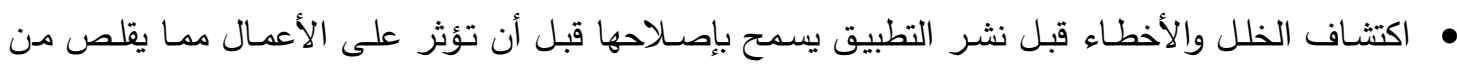
تعطيل وإرباك العمل بسبب فثل البرنامج أو حدوث الأخطاء ويقلص من كلفة إصلاح الخلل.

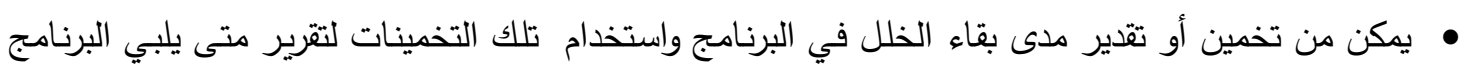
مستوى أو معيار الوثوقية لنشر المنتج.

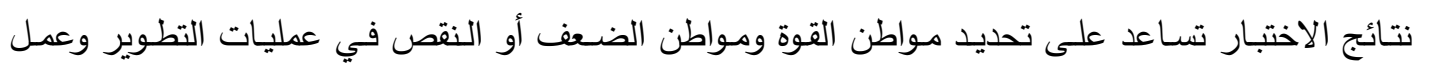

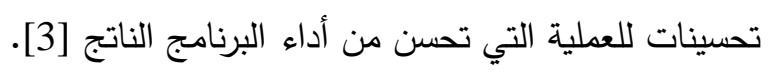
4- 2 - اختبار الصندوق الأبيض يرتكز اختبار الصندوق الأبيض على تحليل الهيكل الداخلي للبرنامج. واختبار الصندوق الأبيض هو

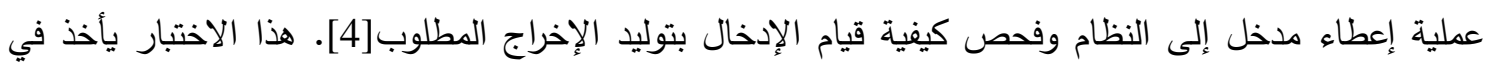
الحسبان الآلية الداخلية للنظام أو المكونات. الشكل (2) يوضح تقدم العمل في اختبار الصندوق الأبيض ويبين الجدول (1) التقنيات لهذا الاختبار [6].

الجدول (1). تقنيات اختبار الصندوق الأبيض

\begin{tabular}{|c|c|}
\hline White Box Testing & اختبارات الصندوق الأبيض \\
\hline Loop Testing & اختبار الدارة البرمجية \\
\hline Branch Testing & الاختبار الفرعي \\
\hline Data Flow Testing & اختبار تدفق البيانات \\
\hline Control Flow Testing & اختبار تدفق السيطرة \\
\hline Basis Path Testing & اختبار المسار الأساسي \\
\hline
\end{tabular}

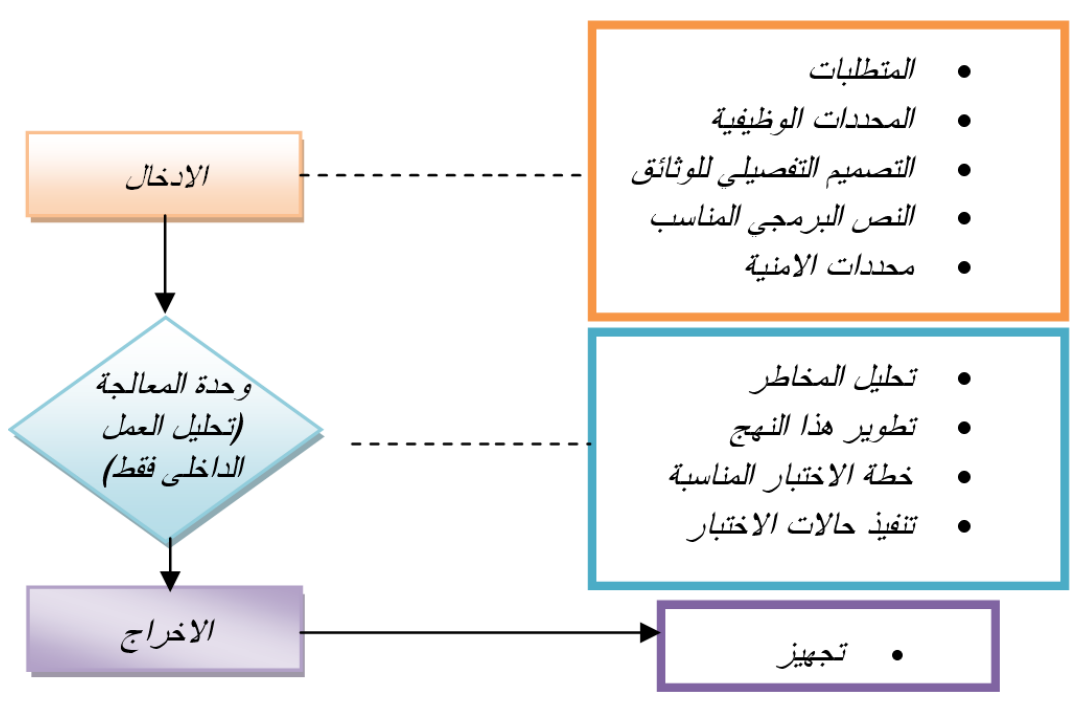

الثكل (2). تقدم العمل في اختبار الصندوق الأبيض 
يكون اختبار الصندوق الأبيض أكثر كلفة وأغلى بكثير من اختبار الصندوق الأسود. ويتطلب إجراؤه توليد الثفرة

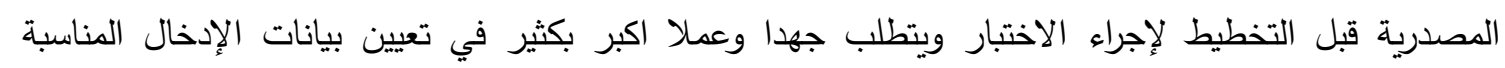

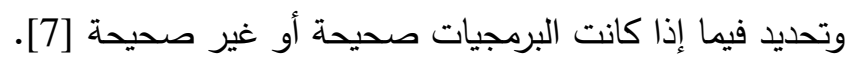

$$
\text { 5- اختبار البرمجيات التلقائي أو الآلي }
$$

الاختبار التلقائي يستخدم البرمجيات لتوليد حالات الاختبار وتنفيذها ومقارنة النتائج ويسجل الأخطاء من

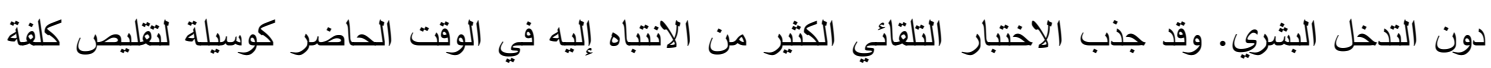
الاختبار واكتثاف أخطاء أكثر وتوفير الوقت الثمين. وبكلمات ابسط هو "كتابة شفرة لاختبار شفرة". معظم عمليات الاختبار التلقائية تُنفذ باستخدام أدوات اختبار خاصة وتتطلب مهارات أكثر تخصصاً من المهارات التي تتطلبها الاختبارات اليدوية [8]. الاختبار الشامل يمكن تتفيذه فقط بواسطة جعل عملية الاختبار أوتوماتيكيا. المنافع المستحصلة منه هي تقليص الوقت المستهلك وتقليص الجهود وكلفة الاختبار البرمجي. وتتكون أدوات الاختبار

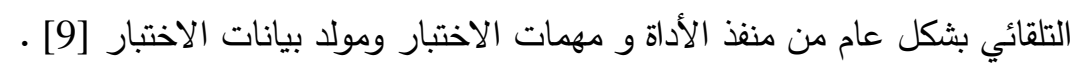

\section{6 - - 6 التكوين التلقائي لحالات الاختبار}

هناك أسلوب واحد لتوليد حالات الاختبار وهو الاختيار العشوائي لبيانات الاختبار إلى أن يتم الاقتتاع

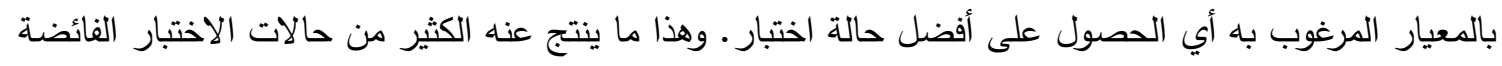
عن الحاجة لأن الكثير من حالات الاختبار سوف تتمرس أو تفحص نفس المسارات [10]. لتوليد حالات الاختبار

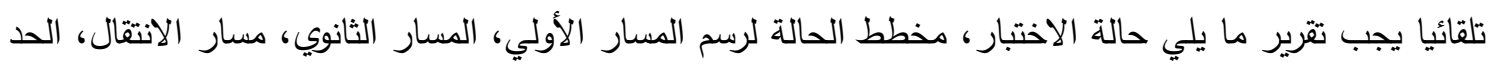
أو الحافة، نطاق المسار [11]. الغرض من إنشاء مخطط تدفق السيطرة CFG هو تمثيل مخططي مفصل لوحدة

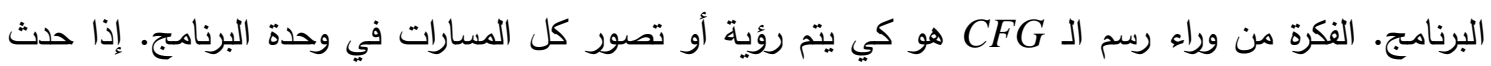

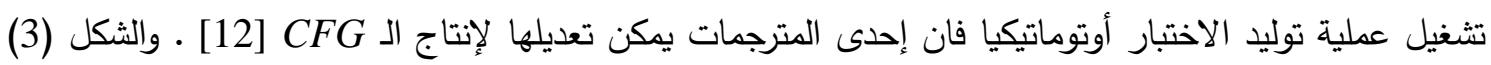
يبين عملية توليد حالات الاختبار .

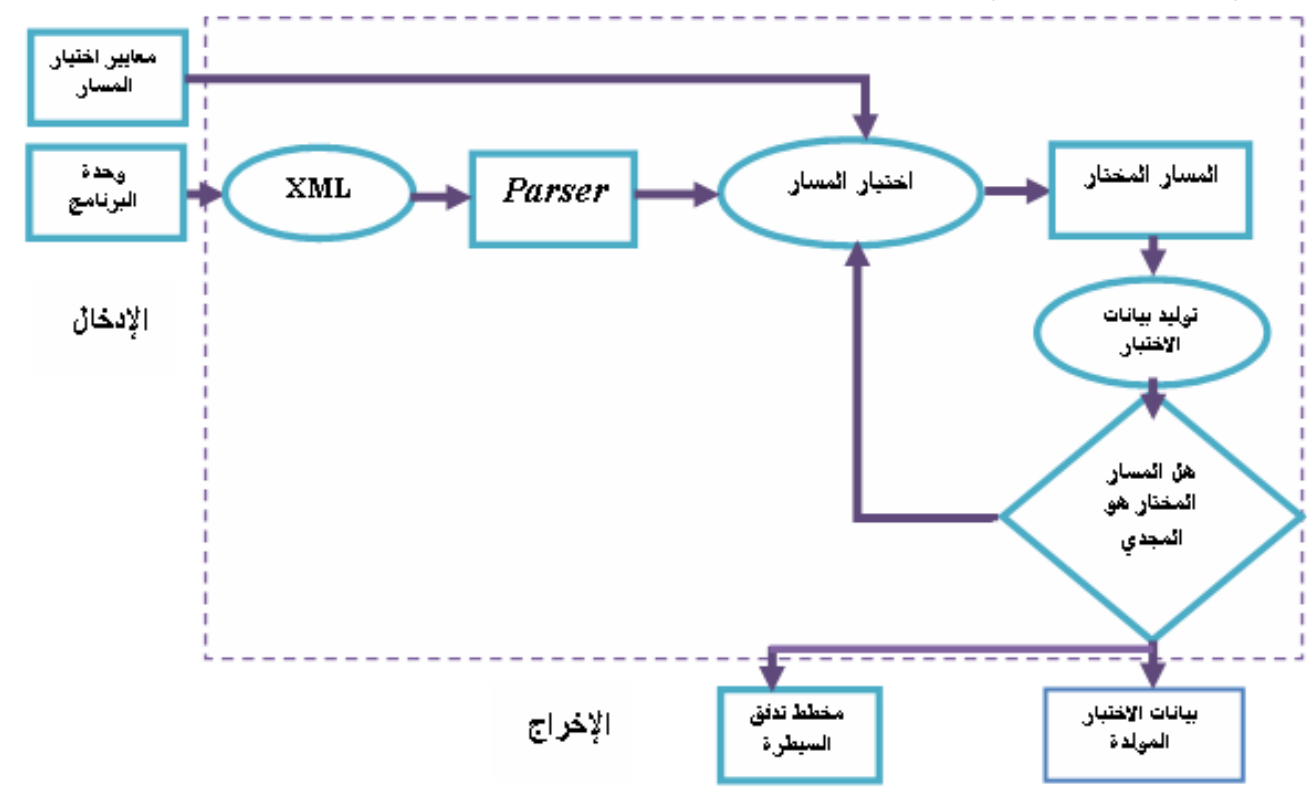

الثكل (3). عملية توليد حالة الاختبار 
الإدخالات في عملية توليد الاختبار

• الثفرة المصدرية لوحدة البرنامج

• معيار اختيار المسار : الحالة ، الفرع.

XML إنشاء

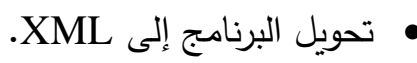

• تحليل المسارات التي تم الحصول عليها من تقرير Xml.

اختيار المسارات

• يجري اختيار المسارات من الـ CFG ليلبي معيار اختيار المسار ويجري انجازه بوساطة ملاحظة تركيبة الـ

.CFG

اختبار قابلية التنفيذ للمسار

• الفكرة من وراء فحص قابلية التتفيذ لمسار جرى اختياره هو لمقابلة أو ملاءمة معيار اختيار المسار . وهناك

نوعان من المسارات:

- مسار قابل للتتفيذ: مدخلاته موجودة ولهذا فان المسار يتم تتفيذه.

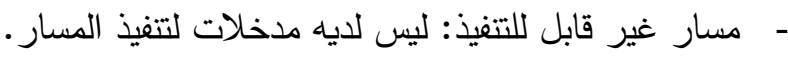

7- - 2 - تنفيذ حالة الاختبار

الخطوة التالية في عملية الاختبار هي تتفيذه. إذ يجري تكوين برنامج متكامل لاختبار النظام بعد الانتهاء

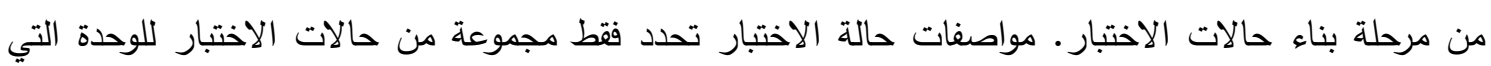

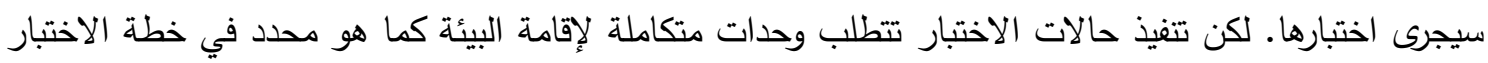
ومواصفات حالة الاختبار [10].

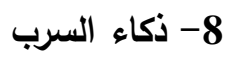

منذ أكثر من خمسين عاماً اثبت علماء البيولوجيا وجود أنواع متعددة من أشكال الذكاء منبثقة من مجتمع الحشرات والأسماك والطيور أو الثذييات. داخل كثيب النمل وأسراب النمل الأبيض ومستعمرات النحل وأسراب الطيور والأسماك لا يمتلك الفرد الواحد القدرة العصبية الضرورية. على الرغم من ذلك فان التفاعل المجرد البسيط ولني

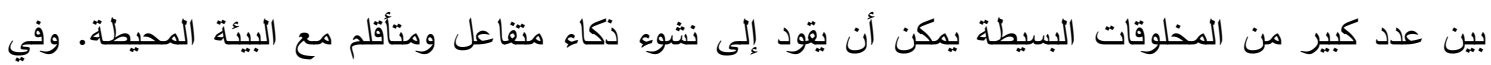

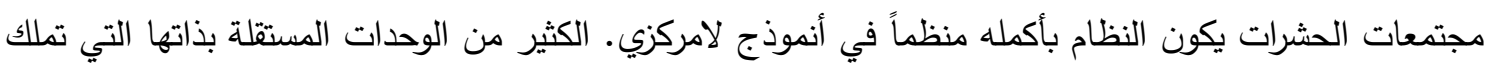

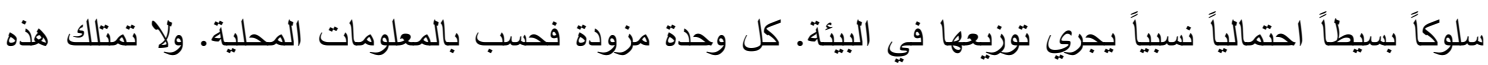
الوحدات أي تمثيل أو معرفة واضحة بالتركيبة الشاملة التي من المفترض أن تقوم بإنتاجها أو تطويرها. ولا أية

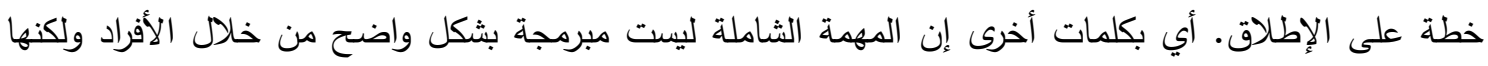

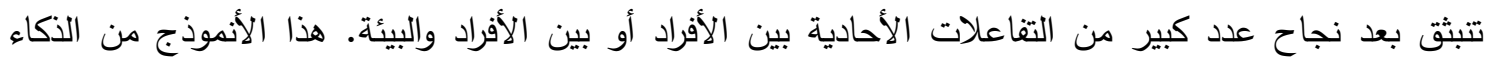

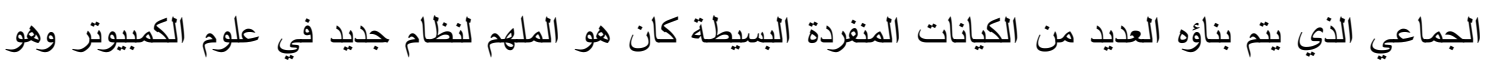


PSO 1-8 خوارزمية سرب الطيور

إن اختيار عوامل الـ PSO الجيدة بطريقة سهلة جرى تقديمها من قبل Pedersen et al 2000 والذي

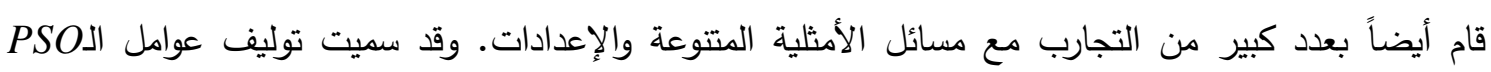

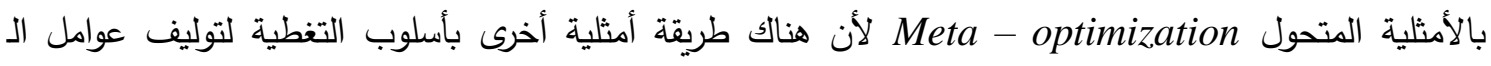

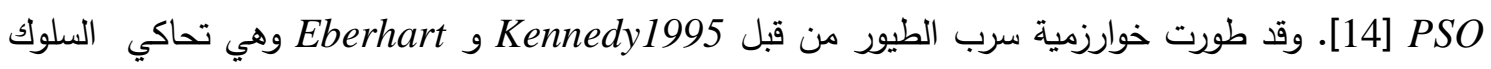
الاجتماعي لأسراب الطيور والأسماك والطرائق التي تستخدمها هذه الأسراب لإيجاد المأوى والمسكن ومصنادر

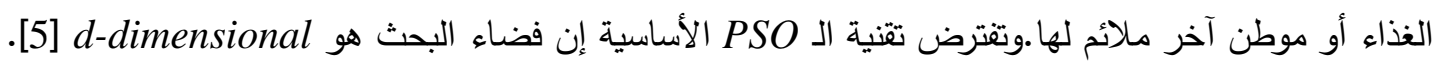
كل عضو يُسمى بالجسيم، وكل جسيم

$$
\begin{aligned}
& \text { كالآتي } \\
& \text { مجموعة جسيمات n في السرب تُمى الأفراد. }
\end{aligned}
$$

أفضل موقع سابق للجسيم (الموقع الذي يعطي أفضل قيمة لياقة) يُسمى الجسيم الأفضل ويُوصف:

$$
P B_{i}=\left[p b_{i 1}, p b_{i 2}, \ldots \ldots \ldots . . . . . . . . . ., p b_{i d}\right]
$$

أفضل موقع من بين أفضل مواقع الجسيم المتحققة حتى الآن يُسمى الثامل الأفضل Global Best

$$
\begin{aligned}
& \text { ويُوصف: }
\end{aligned}
$$

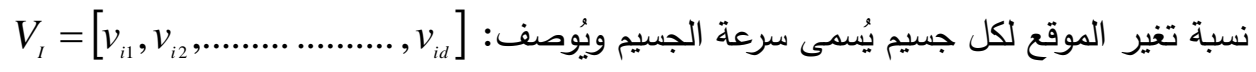

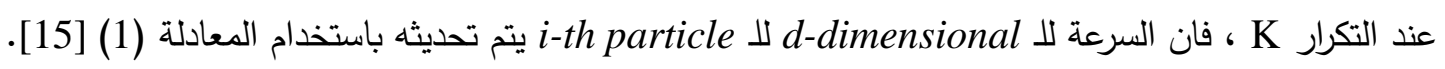

$$
V_{i d}(K+1)=w v_{i d}(k)+c_{1} r_{1}\left(p b_{i d}(k)-x_{i d}(k)\right)+c_{2} r_{2}\left(g b_{i d}(k)-x_{i d}(k)\right)
$$

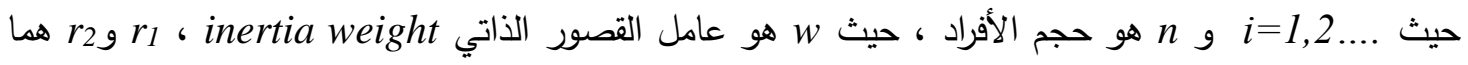

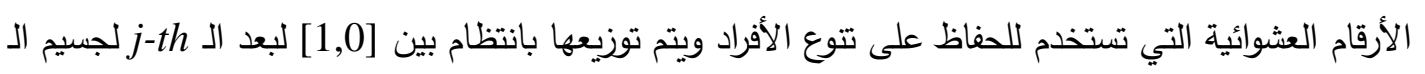

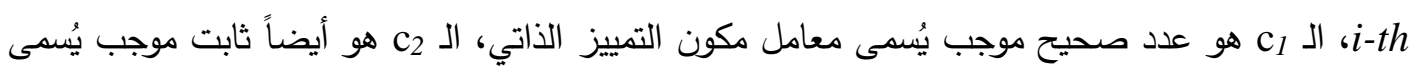

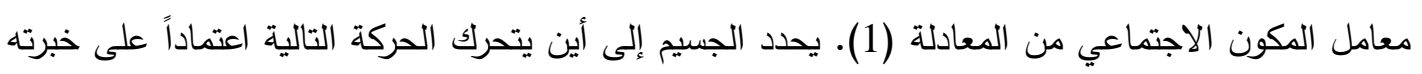

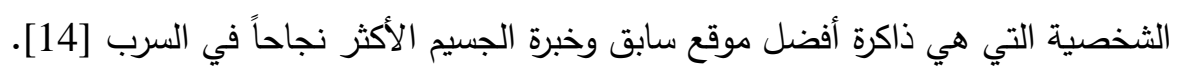
موقع i-particle يتم تحديثه بواسطة المعادلة (2) [15]:

$x_{i d}(k+1)=x_{i d}(k)+V_{i d}(k+1)$

المتغير W ينظم عملية الاستبدال بين قابليات الاستكثاف الثاملة العالمية " الواسعة النطاق " للسرب

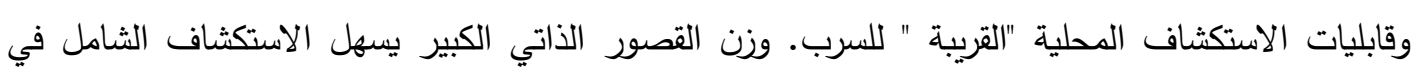
حين الصغير يميل إلى تسهيل الاستكثاف المحلي الثامل. القيمة المناسبة لوزن القصور الذاتي عادةً تقدم

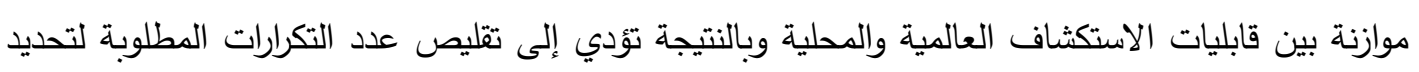
موقع الحل الأفضل. في البداية وزن القصور الذاتي هو مجموعة من الثوابت. وهكذا فان القيمة الأولية هي

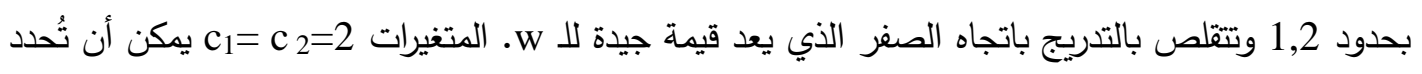
كقيم قياسية. ويشير عدد من نتائج التجارب إلى أن قد تكون 20. المعادلة (1) تصف كيفية تحديث السرعة ديناميكيا. المعادلة (2) تحديث موقع الجسيمات الطائرة [16]. 


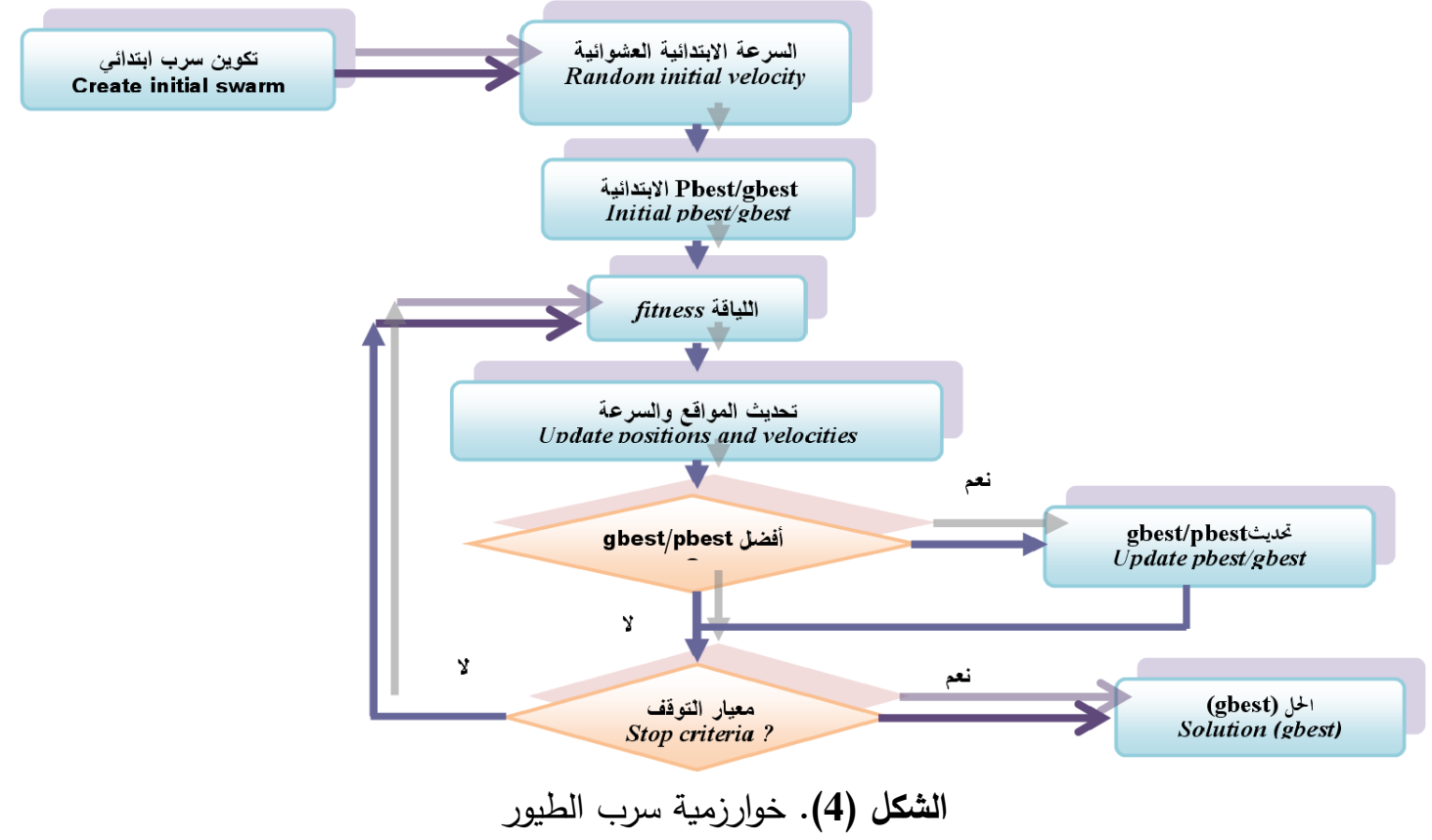

2-8

في العام 2006 قدمت خوارزمية أساسية في ذكاء السرب من قبل Che et. al. وقد عُرفت بخوارزمية سرب القطط أو الـ CSO. وكما يتبين من اسمها بشكل واضـح فان هذه الخوارزمية تستند إلى سلوك القطط.

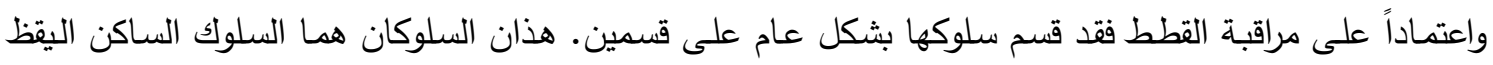
وسلوك الحركة "المطاردة" النشط. وعلى الرغم من أنها تبدو كسولة وتقضي معظم وقتها في الراحة ولكن من خلال

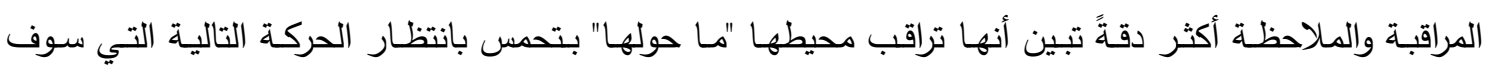
تتخذها[17]. خوارزمية سرب القطط CSO هي إحدى خوارزميات الأمثلية الاستدلالية الجديدة المرتكزة على ذكاء

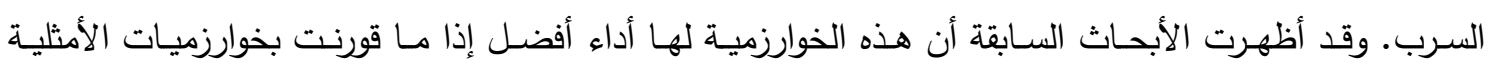
الاستدلالية الأخرى: كخوارزمية سرب الطيور PSO والـ PSO ذو الوزن weighted - pso في حالات تصغير

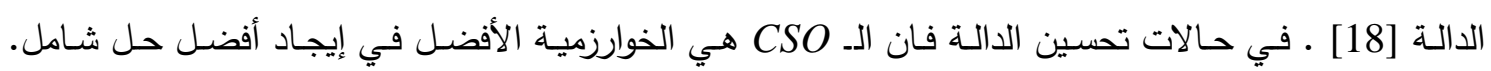

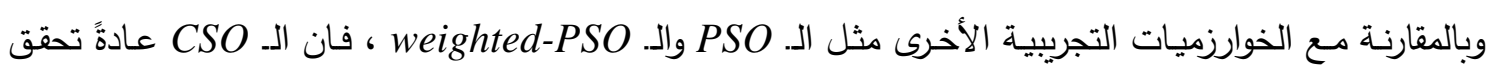
نتائج أفضل. ولكن في بعض الأحيان وفي عدد من الحالات فان الـ CSO الخالصة تستغرق وقتاً طويلاً في إيجاد

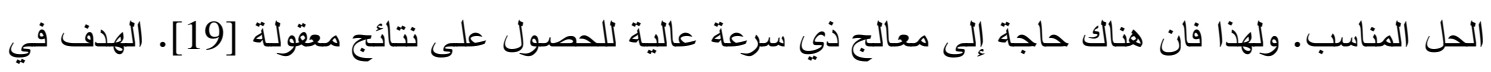

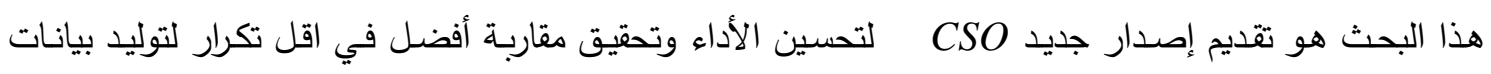
الاختبار •

\section{1-2-8 وصف نواة الـ CSO}

من اجل دمج هذين الأسلوبين في خوارزمية يجب تعريف نسبة الامتزاج MR الذي يملي أوامر اتحاد أسلوب البحث مع أسلوب تعقب الأثر • ويقرر MR كم من القطط التي سوف يجري تحريكها بعملية أسلوب البحث.

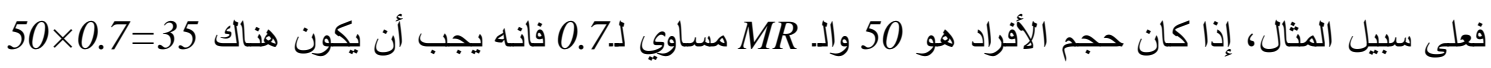


قطاً متحركاً إلى أسلوب البحث و15 قطاً متحركاً إلى أسلوب التعقب في هذا التكرار. اذن عملية الـ CSO يمكن تلخيصها كالآتي[19]:

أولاً - إنشاء N من القطط وتحديد قيم ابتدائية للموقع، والسرع المؤشر لكل قط. ثانياً - تخمين قيمة اللياقة لكل قطة على حسب دالة اللياقة والاحتفاظ بأفضل قط في الذاكرة. ثالثاً - يجري تطبيق القط في مجال البحث أو طور التعقب على حسب مؤشر flag القطة. رابعاً - بعد الانتهاء من العملية يجري التقاط عدد القطط ووضعهم في طور البحث أو طور التعقب وفقاً لقيمة .MR

خامساً- التحقق من حالة الانتهاء فإذا كانت مرضية ينتهي البرنامج وإلا فالرجوع إلى الخطوة الثانية.

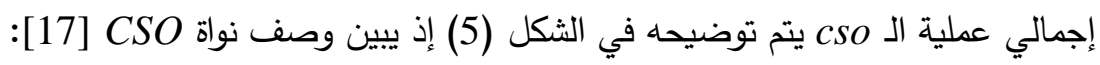

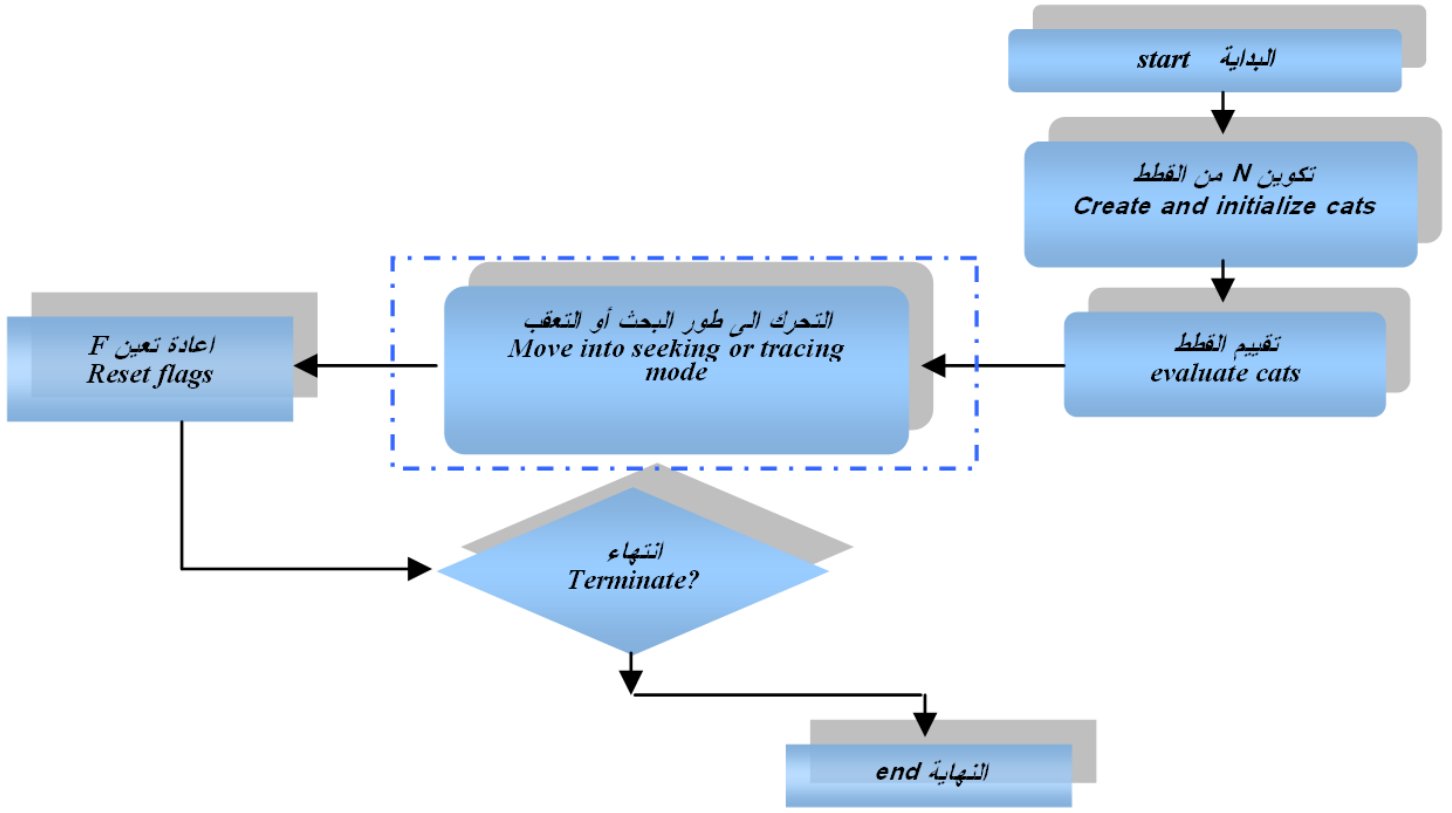

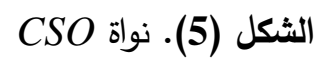

2-2-8 وصف لخوارزمية سرب القطط

خوارزمية سرب القطط تحاكي السلوك الطبيعي للقطط. تكون القطط دائما متيقظة وبطيئة الحركة. وهذا السلوك يمثل طور البحث. فعندما يتم التحسس بوجود فريسة فان القط يطارد بسرعة كبيرة جدا. هذا السلوك أي المطاردة بسرعة عالية يمثل طور التعقب ـ وقد جرت صياغة هذين الطورين رياضياً لحل مسائل الأمثلية. وقد فئد استخدمت مواقع القطط لتمثل مجموعة الحل. وكل قط له موقع وسرعة لكل بعد وقيمة لياقة. فضـلا عن مؤشر يستخدم لتحديد فيما إذا كان القط في طور البحث أم في طور التعقب [20]. وقد اتضح مما سبق فان الـ CSO لـ له طوران ثانويان: طور البحث وطور تعقب الأثر ـ لدمج هذين الطورين في خوارزمية تعرف نسبة امتزاج

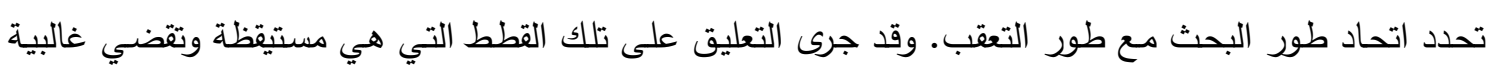

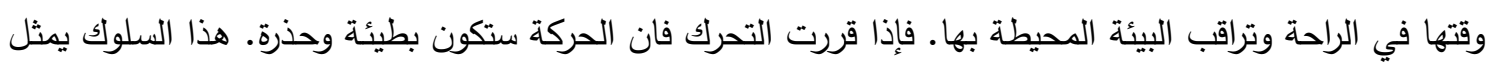
طور البحث [21]. 


\section{فيما يأتي خطوات خوارزمية سرب القطط:}

الخطوة الأولى: تكوين الخطوة الثانية: نشر القطط عشوائياً في أبعاد M-dimensional فضاء الحل وإعطاء القيم عشوائياً التي تكون في

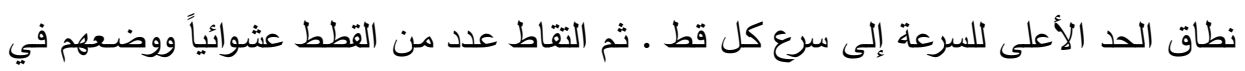

$$
\text { طور التعقب وبنسبة MR=20\% والقطط الآخر } 80 \% \text { توضع في طور البحث. }
$$

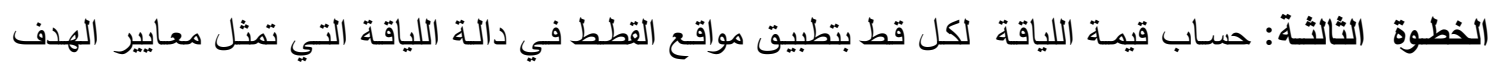

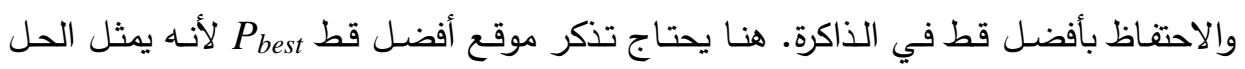

$$
\text { الأفضل حتى الآن. }
$$

الخطوة الرابعة: تحريك القطط وفقاً لمؤشراتها، فإذا كان القط القط

$$
\text { البحث وإلا يتم تطبيقه في عملية التعقب. }
$$

الخطوة الخامسة: يجري التقاط عدد من القطط ووضعهم في طور التعقب وفقاً لا. MR ثم وضع بقية القطط في لتطي

$$
\text { طور البحث. }
$$

الخطوة السادسة: التحقق من شروط الانتهاء فإذا كانت مرضية يجري إنهاء البرنامج وإلا فستعاد الخطوات الثالثة

$$
\text { إلى الخامسة [21]. }
$$

والثكل (6) يبين المخطط الانسيابي لخوارزمية سرب القطط CSO [21]. والثكل (7) يبين الدخطط العام لسلوك سرب القطط بطوريها البحث وتعقب الأثر [22].

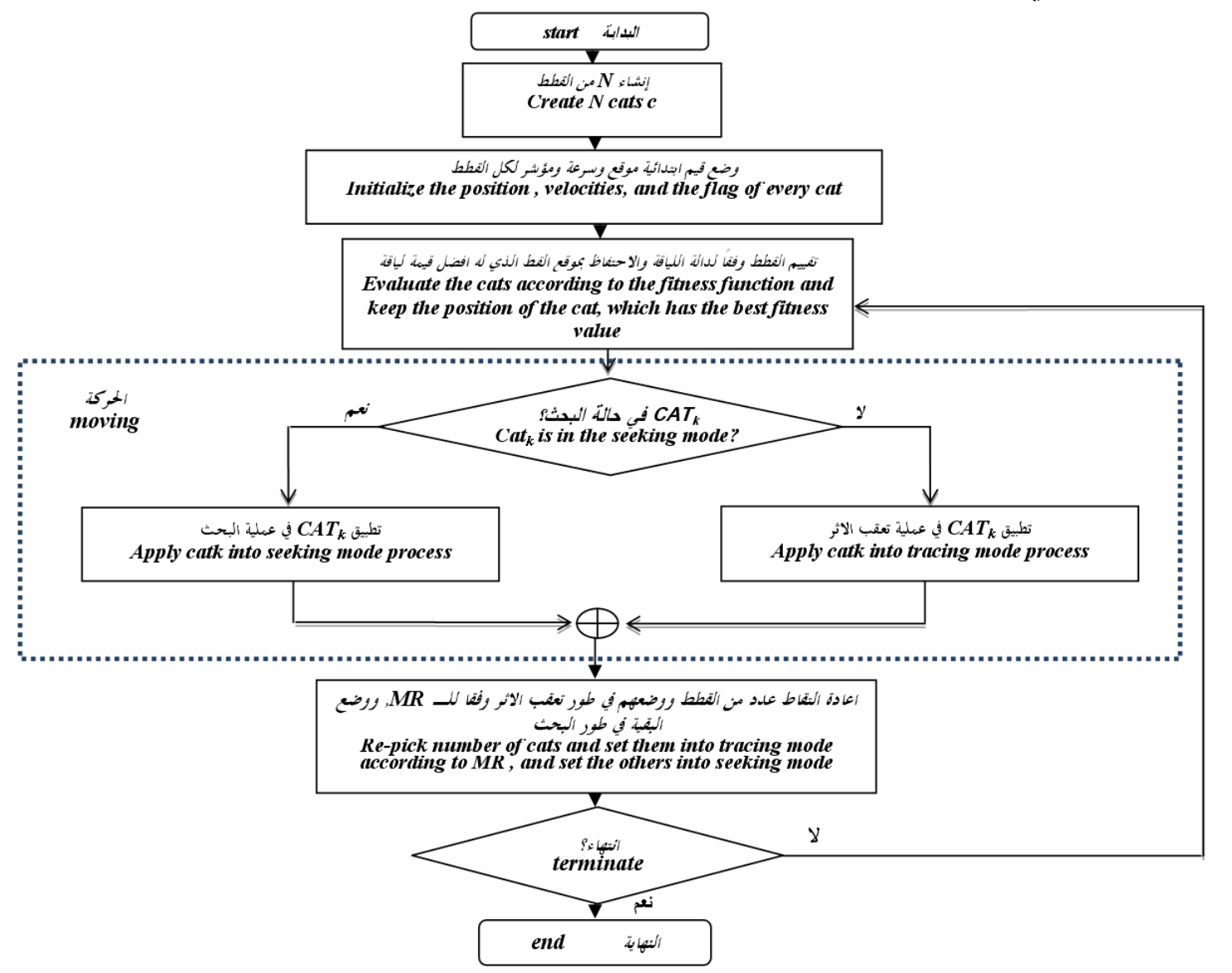

الثكل (6). المخطط الانسيابي لخوارزمية الـ CSO 


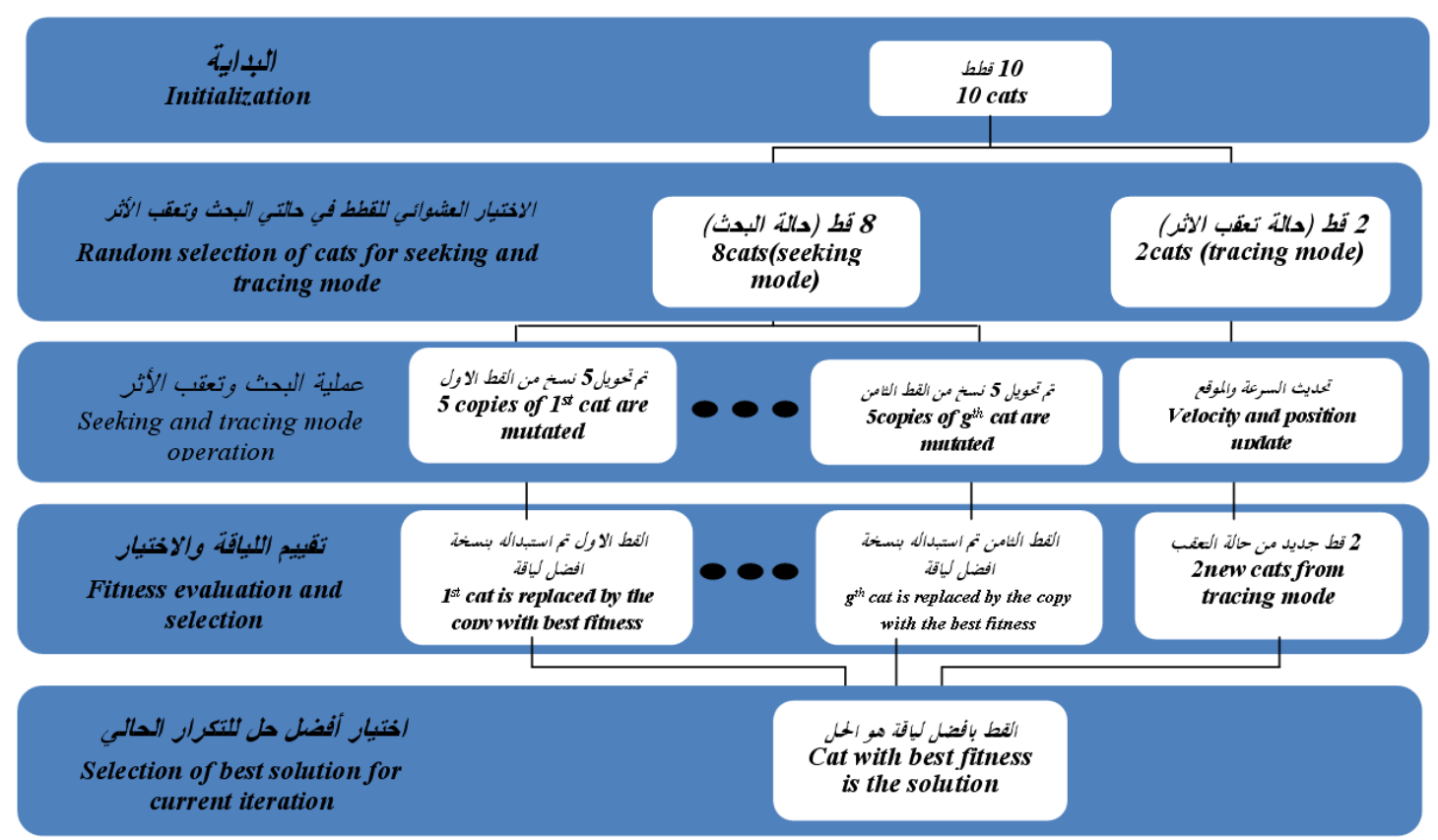

الثكل (7). المخطط العام لسلوك خوارزمية سرب القطط

9- آلية استخدام التقنيات الاككائية في توليد حالات الاختبار

إن عملية استخدام تقنيات الذكاء الاصطناعي و توظيفها في مساعدة هندسة البرمجيات يمكن أن يعطي نتائج ذات دقة عالية وكلفة قليلة وسريعة، وقد استخدمت في هذا البحث تقنيات السرب في توليد بيانات الاختبار أوتوماتيكيا التي تحقق تغطية عالية للشفرة وكان العمل في محورين: 1- استخدام خوارزمية سرب الطيور في توليد بيانات الاختبار . 2- استخدام خوارزمية سرب القطط في توليد بيانات الاختبار .

وبداية ينبغي النظر إلى الآليات المشتركة بين هاتين الخوارزميتين (دالة اللياقة) المستخدمة في توليد بيانات

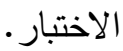

دالة اللياقة: تعد دالة اللياقة من أهم المراحل في خوارزميات السرب لما لها من تأثير عال على سرعة خوارزمية الطيور وخوارزمية القطط ودقتهما، إذ أن دالة اللياقة المقترحة كما في المعادلة الآتية: $F(T)=(B(T)+R(t)) / 2$ الاقتراب من قيمة الحدود: إن فرص الأخطاء تكون غالباً في قيم الحدود لذلك فإن حالات الاختبار القريبة من قيم

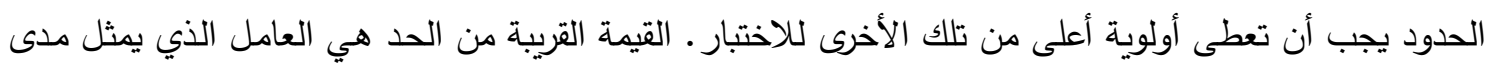

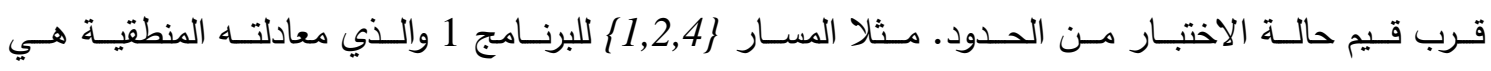

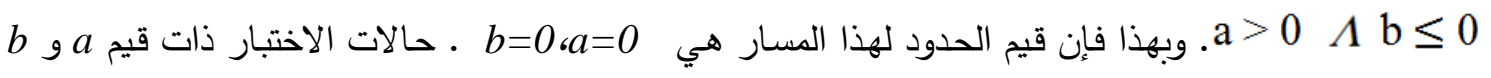
القريبة من الصفر تعطى أولوية أكبر من تلك الأبعد عن الصفر • وكما في الاحتمالية فإن هذا العامل يساهم أيضاً في اختيار أي حالة اختبار معينة. وأكثر عامل لأي مجموعة اختبار Test suit يرفع احتمالية مجموعة الاختبار

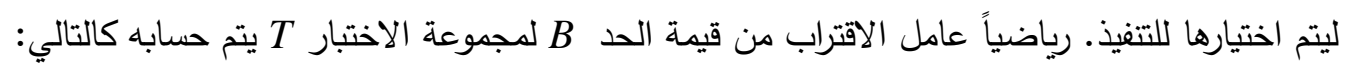
$B(T)=B\left(t_{1}\right) * B\left(t_{2}\right) * \ldots * B\left(t_{n}\right)$

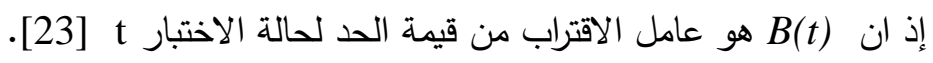


معظم أدوات الاختبار الآلي تستخدم معيار تغطية الفرع لاختيار حالات الاختبار ـ تغطية الفرع تحسب تفات من نسبة عدد الحافات التي تم تغطيتها من قبل حالات الاختبار مقسوماً على حافات مخطط تدفق السيطرة للبرنامج المراد اختباره، إذ انه كلما زادت هذه النسبة حصل الاقتراب من الوصول إلى حالة الاختبار المثالية التي

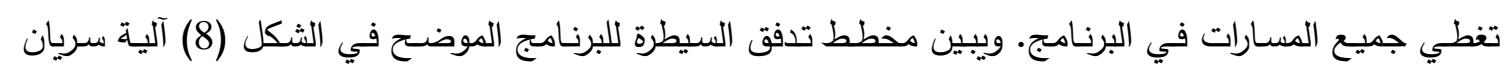

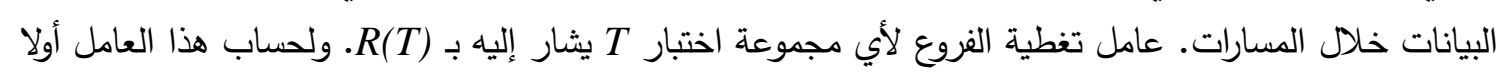

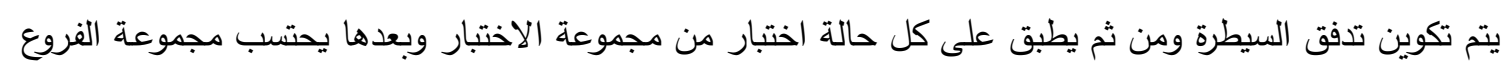

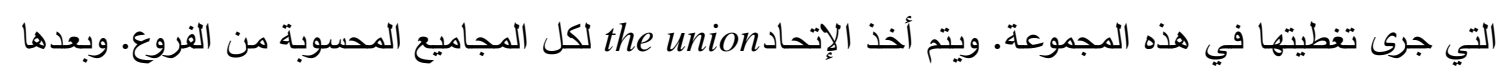
يحتسب عدد العناصر للمجموعة الناتجة وليكن n ومن ثم تحسب قيمة تغطية الفروع من الآد المعادلة الآتية: $R(T)=n / e$

إذ أن e تمثل العدد الكلي لحافات مخطط تدفق السيطرة للبرنامج المراد اختباره، وان n تمثل العدد الكلي للحافات

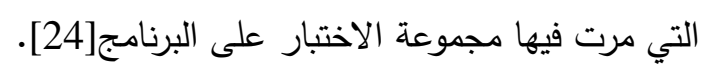

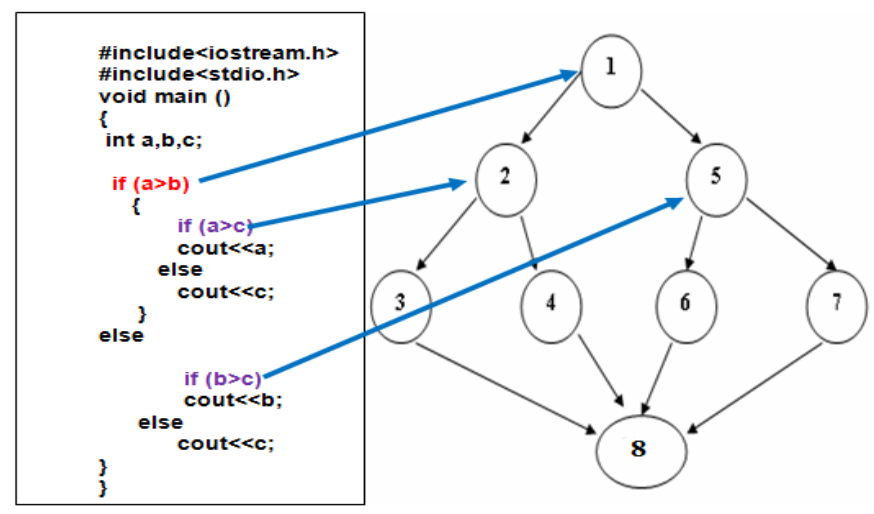

الثكل (8). مخطط تدفق السيطرة للبرنامج

1-9 خوارزمية سرب الطيور في توليد حالات الاختبار أولا: وحدة التدريب

يجري في هذه الوحدة تدريب الخوارزمية على توليد حالات الاختبار بواسطة تحليل الثفرة البرمجية للبرنامج

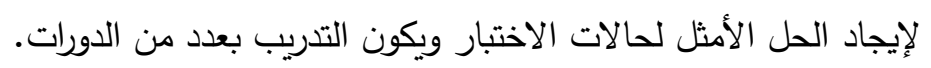

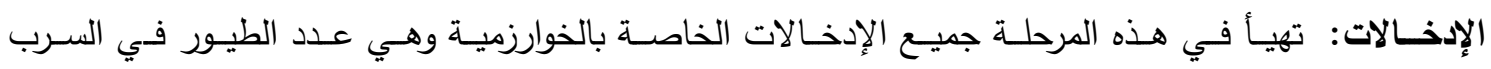

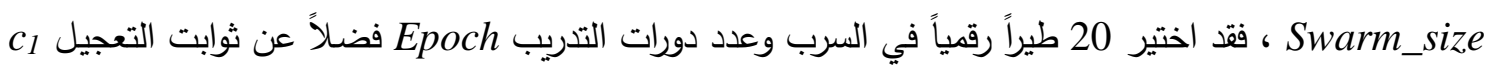
و 2 والأوزان الخاصة بالمعادلات رقم (1)، (2) فضلا عن إدخال بيانات التدريب الممثلة بمصفوفة أحادية تتكون من 20 طائراً وكل طائر في السرب عبارة عن مصفوفة ثائية تعبر عن مجموعة الاختبار (التي تضم مجموعة من الأن

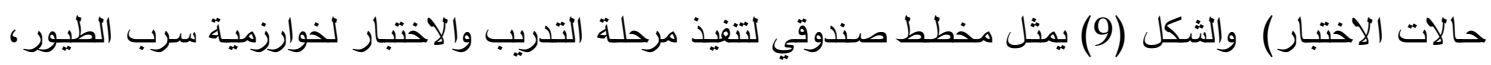
والجدول (2) يبين مدخلات خوارزمية سرب الطيور . 


\begin{tabular}{|c|c|}
\multicolumn{1}{c|}{ (الجدول (2). يبين مدخلات خوارزمية سرب الطيور } & Value \\
\hline Parameter & 20 \\
\hline No. Of particles & 0.9 \\
\hline Inertia weight w1 & 0.6 \\
\hline Inertia weight w2 & 1 \\
\hline Velocity bound & $-32.768-32.768$ \\
\hline Boundary condition & 1000 \\
\hline Termination & 2.1 \\
\hline cl & 2.1 \\
\hline c2 & \\
\hline
\end{tabular}

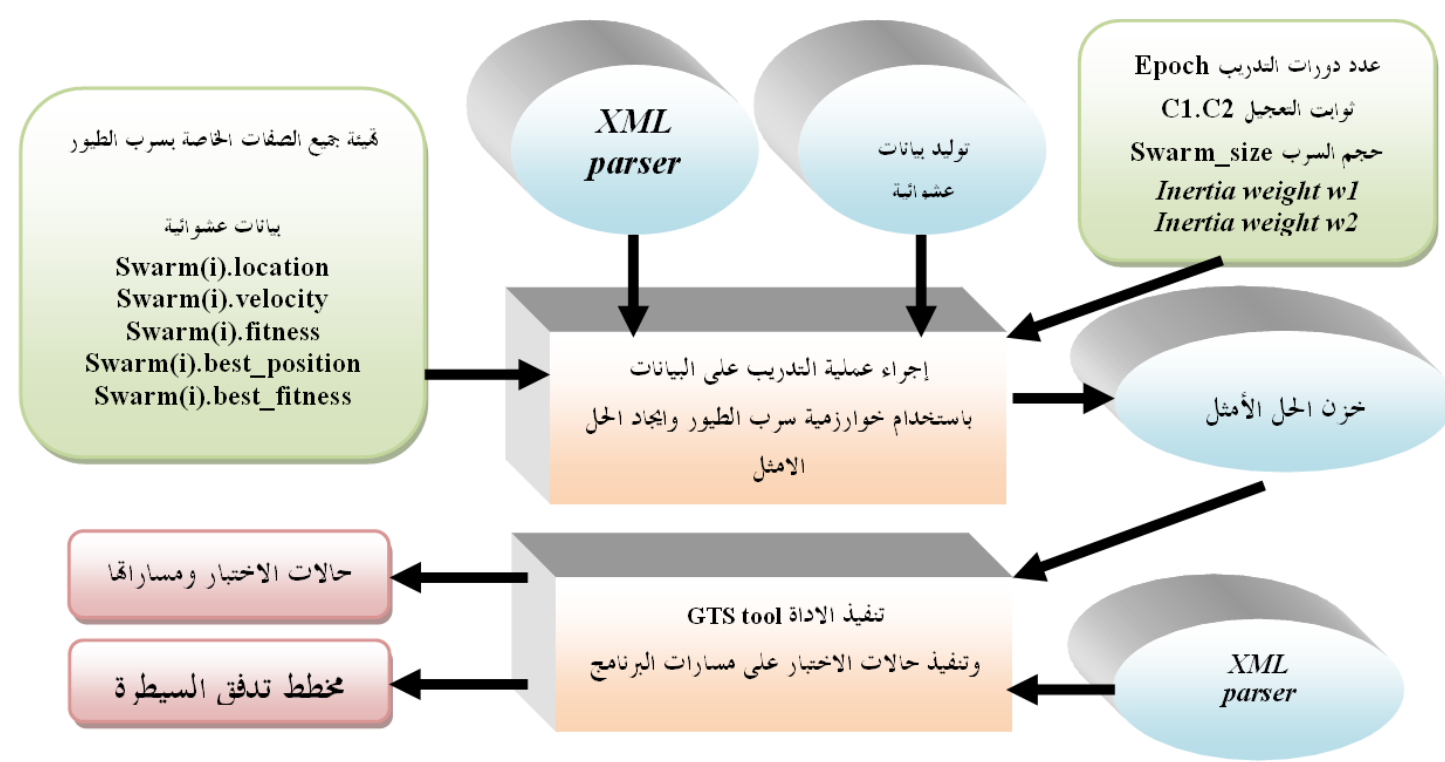

الثكل (9). المخطط الصندوقي لتنفيذ مرحلة التدريب والاختبار لخوارزمية سرب الطيور

المعالجة: لكل طير رقمي i معلومات خاصة بهِ في بداية المعالجة تهيأ كل هذه المعلومات ببيانات عشوائية هي:

$$
\text { • موقع الطير في فضاء البحث. }
$$

$$
\text { • • مرعة الطير الخاصة في فضاء البحث. }
$$

• قيمة دالة اللياقة الخاصة بالطير الرقمي وأفضل قيمة لدالة اللياقة حصل عليها هذا

$$
\text { الطير swarm(i).best_fitness }
$$

• أفضل موقع حصل عليه الطير في السرب أي أفضل موقع اقترب فيه الطير من الحل الأمثل في فضـاء

$$
\text { البحث. }
$$

يتم إيجاد دالة اللياقة الخاصة بالطير الرقمي التي يجري مقارنتها مع أفضل دالة لياقة حصل عليها الطير swarm(i).best_fitness الجديدة، فضلاً عن استبدال قيمة موقع الطير بالموقع الجديد صاحب أفضل دالة لياقة، أما إذا لم تكن دالة اللياقة

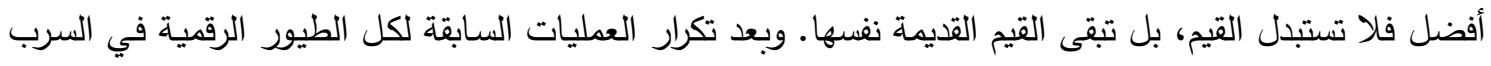
swarm(i).best_fitness يجري إيجاد أفضل موقع حصل عليه أفضل طائر بالنسبة للسرب، حيث تتم مقارنة

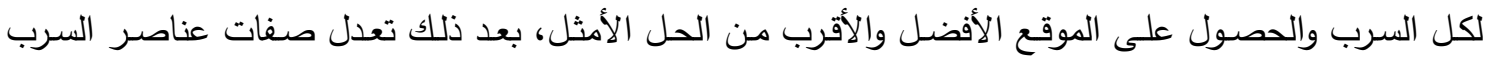


جميعها من ناحية الموقع والسرعة حسب أفضل طير رقمي إذ تُطبَّق المعادلة رقم (1) وتحسب سرعة الطير الرقمي

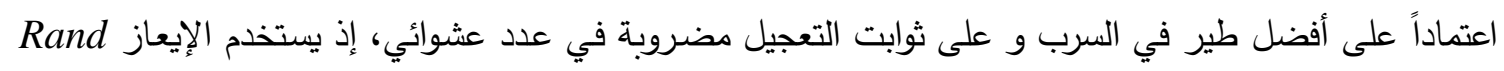
لتوليده مباشرة في المعادلة. والمعادلة رقم (2) يجري فيها تحديث موقع الطير في السرب. تُكرر العمليات السابقة

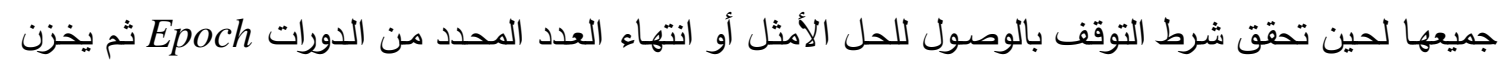

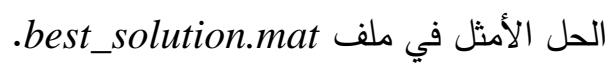
المخرجات: أفضل قيم لحالة الاختبار لاستخدامها لاحقاً في عملية اختبار البرنامج ،مسارات البرنامج، رسم مخطط تدفق السيطرة. ثانيا: وحدة الاختبار تختبر في هذه الوحدة كفاءة الحل الأمثل الذي استحصل عليه في مرحلة التدريب. الحل الأمثل gbest.test الذي يمثل أفضل مجموعة اختبار Test Suite التي استحصلت في عملية التدريب والتي تتكون من مصفوفة ثنائية عدد صفوفها يمثل عدد مسارات البرنامج المراد اختباره والتي تسمى حالة الاختبار

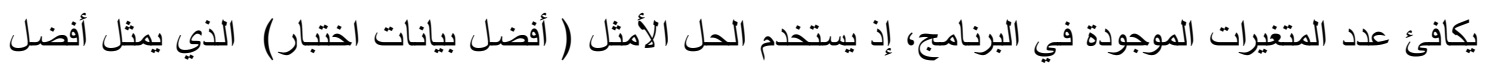

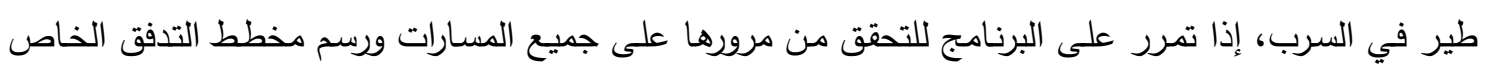

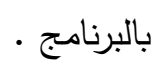

2-9 خوارزمية سرب القطط في توليد حالات الاختبار أولا: وحدة التدريب

يحدث في هذه الوحدة تدريب الخوارزمية على توليد حالات الاختبار عن طريق تحليل الثفرة البرمجية

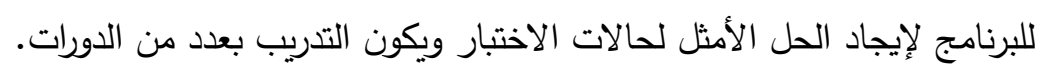

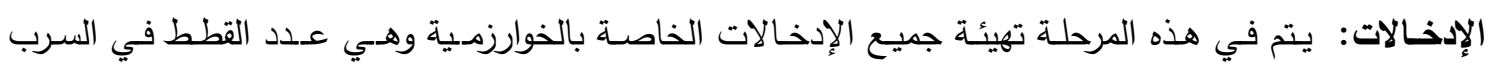

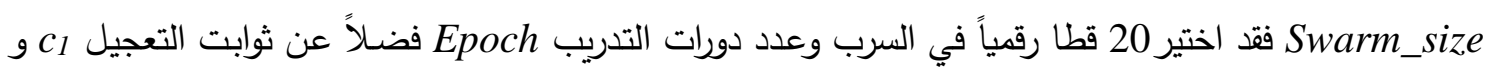
$V_{k . d}=V_{k . d}+r l . c l\left(X_{b e s t . d}-X_{k . d}\right)$ c والأوزان الخاصة بالمعادلات رقم (6) (6)، (7) (7) الآتيتين:

$X_{k . d}=X_{k . d}+V_{k . d}$

$$
\begin{aligned}
& \text { حيث أن: } \\
& \text { : Xest,d } \\
& \text {. } \text { cat }_{k} \text { : الموقع الصحيح } \\
& \text { r } 1 \text { : متغير عشوائسي يعود إلى ل1 } 10,1 \\
& \text { c1 }
\end{aligned}
$$

فضـلا عن إدخال بيانات التدريب الممثلة بمصفوفة أحادية تتكون من 20 قطا وكل قط في السرب يمثل مصفوفة ثنائية تمثل بدورها مجموعة الاختبار (التي تضم مجموعـة من حالات الاختبار ). والثكل (10) يمثل

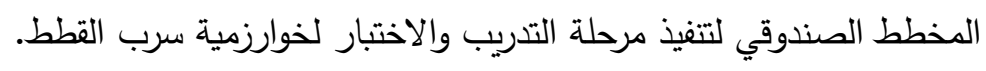


الجدول (3). يبين مدخلات خوارزمية سرب القطط

\begin{tabular}{|c|c|}
\hline Parameter & Value or range \\
\hline No. Of CAT & 20 \\
\hline SMP & 5 \\
\hline$S P C$ & $T-F$ \\
\hline$S R D$ & {$[0-1]$} \\
\hline$C D C$ & 1 \\
\hline$M R$ & RANDOM \\
\hline$C 1$ & 2.1 \\
\hline$R 1$ & {$[0,1]$} \\
\hline$W 1$ & 0.6 \\
\hline$W 2$ & 0.9 \\
\hline
\end{tabular}

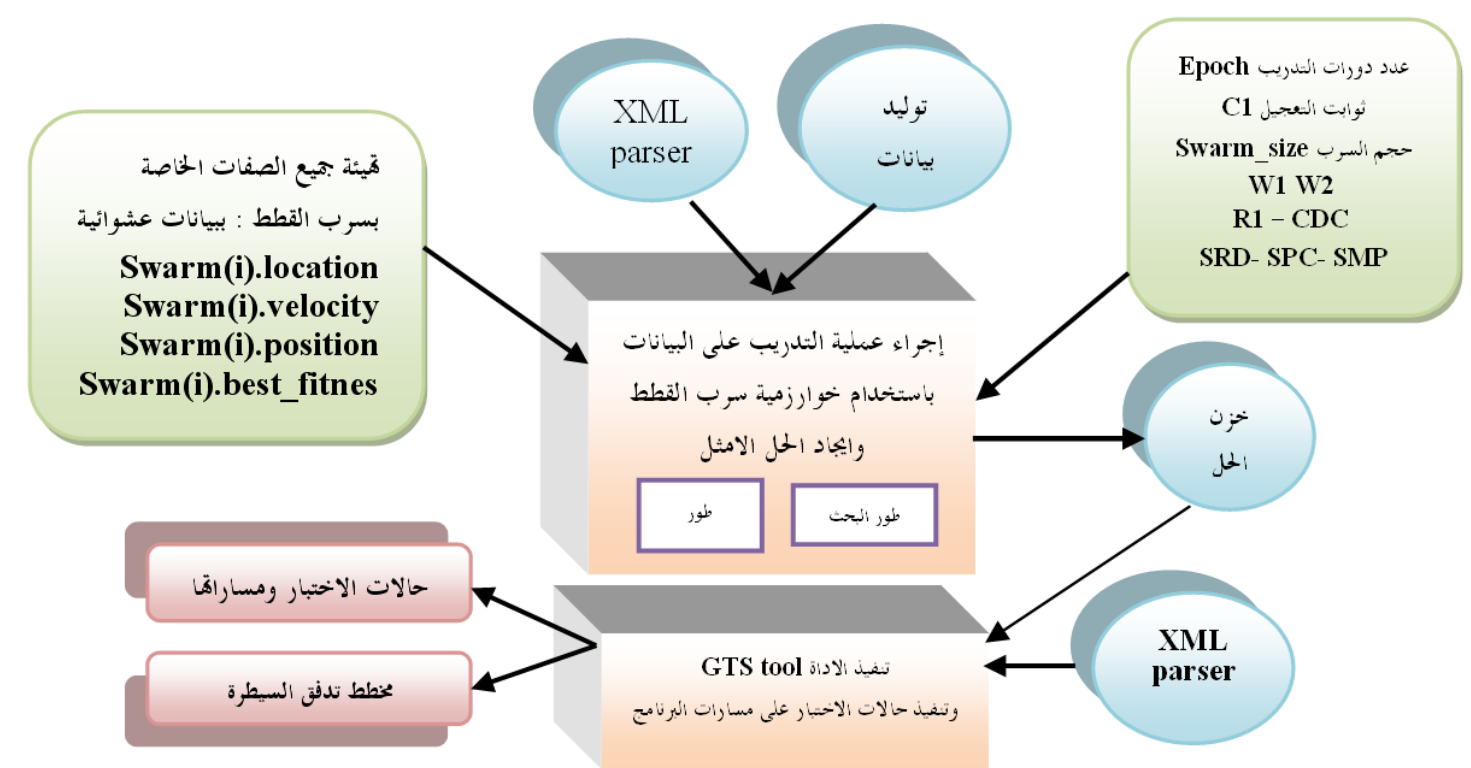

الثكل (10). المخطط الصندوقي لتنفيذ مرحلة التدريب والاختبار لخوارزمية سرب القطط

المعالجة: لكل قط رقمي i معلومات خاصة بهِ في بداية المعالجة وتهيأ هذه المعلومات كلها في بيانات عشوائية

$$
\begin{aligned}
& \text { • موقع القط في فضاء البحث. } \\
& \text { • •رعة القط الخاصة في فضاء البحث. } \\
& \text { • إذ تقسم هذه البيانات في كل دورة على طورين هما : } \\
& \text { أولاً: طور البحث }
\end{aligned}
$$

ينشأ لكل قط في هذا الطور مجموعة من النسخ وعددها خمسة، وهناك متغير يسمى SRD اعتمادا على

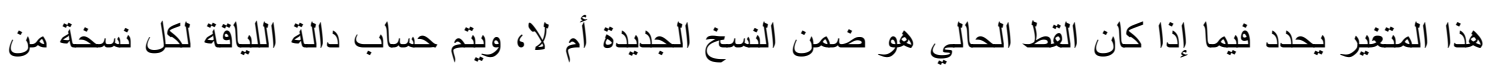
القط، بعدها تحتسب احتمالية بقاء كل نسخة من الجيل حسب المعادلة (8) فالنسخة ذات الاحتمالية الأعلى تمتلك فرصة اكبر للبقاء والانتقال إلى الجيل القادم، وتجرى هذه العملية على جميع القطط الموجودة في هذا الطور، يلي

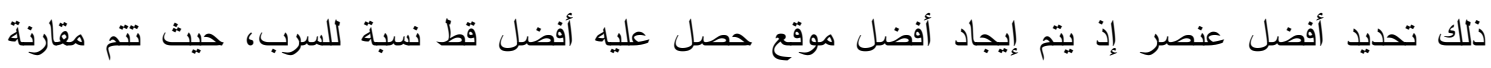
swarm(i).best_fitness 
$\mathrm{p}_{\mathrm{i}}=\frac{|\mathrm{FSl}-\mathrm{FSb}|}{\mathrm{FSmax}-\mathrm{FSmin}},,,,,,,,$, where $0<\mathrm{i}<\mathrm{j}$

If a minimization fitness function is used,

Else

$$
F S_{b}=F S_{\text {min }}
$$

$$
F S b=F S \max
$$

يؤخذ في هذا الطور كل قط من القطط الخاصة بهذه المرحلة على حدة ويحدث سرعته في مجال البحث

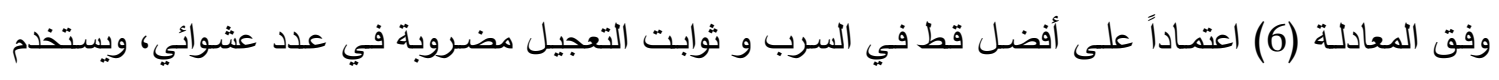

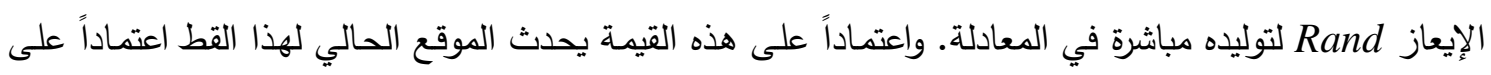

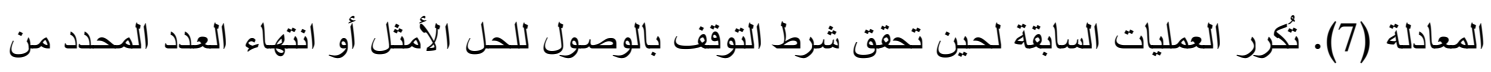

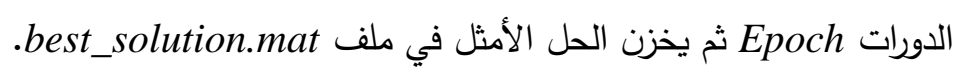
المخرجات: أفضل قيم لحالة الاختبار لاستخدامها لاحقاً في عملية اختبار البرنامج ،مسارات البرنامج، رسم مخطط تدفق السيطرة. ثانيا: وحدة الاختبار: يحدث في هذه الوحدة اختبار كفاءة الحل الأمثل الذي جرى الحصول عليه في مرحلـة

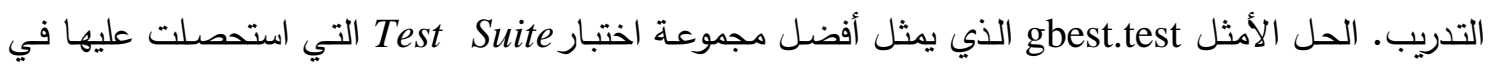
عملية التدريب والتي تتكون من مصفوفة ثنائية عدد صفوفها يمثل عدد مسارات البرنامج المراد اختباره والتي تسمى حالة الاختبار Test Case وعدد أعمدتها يكافئ عدد متغيرات الموجودة في البرنامج، اذ يستخدم الحل

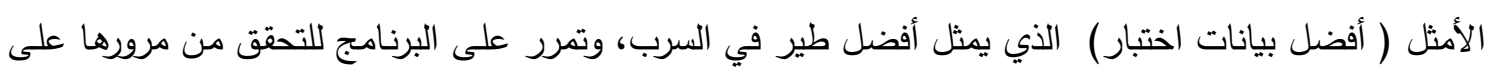
جميع المسارات ورسم مخطط التدفق الخاص بالبرنامج •

\section{0- تحليل الأداة المقترحة}

قبل البدء بعملية التحليل التصصيلية للأداة المقترحة GTS tool يجب البدء بوصفها بثكل عام وبطريقة

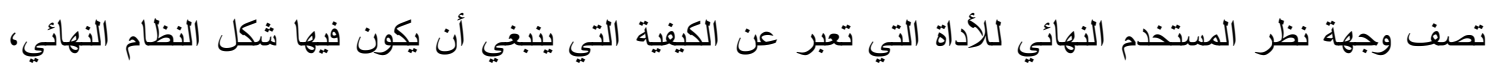

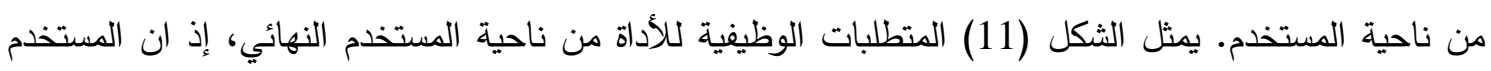
يتعامل مع الثفرة البرمجية المصدرية للبرنامج المراد اختباره وبيانات حالات الاختبار المولدة باستخدام تقنيات السرب التي تستخدم لفحص الثفرة البرمجية المصدرية، وأيضاً توفر الأداة مخطط رسومي لتدفق السيطرة لبيانات

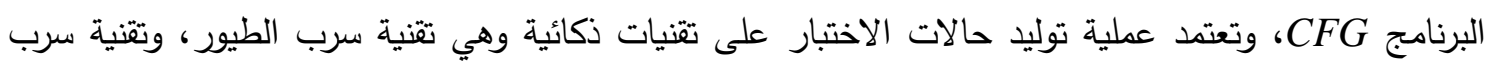




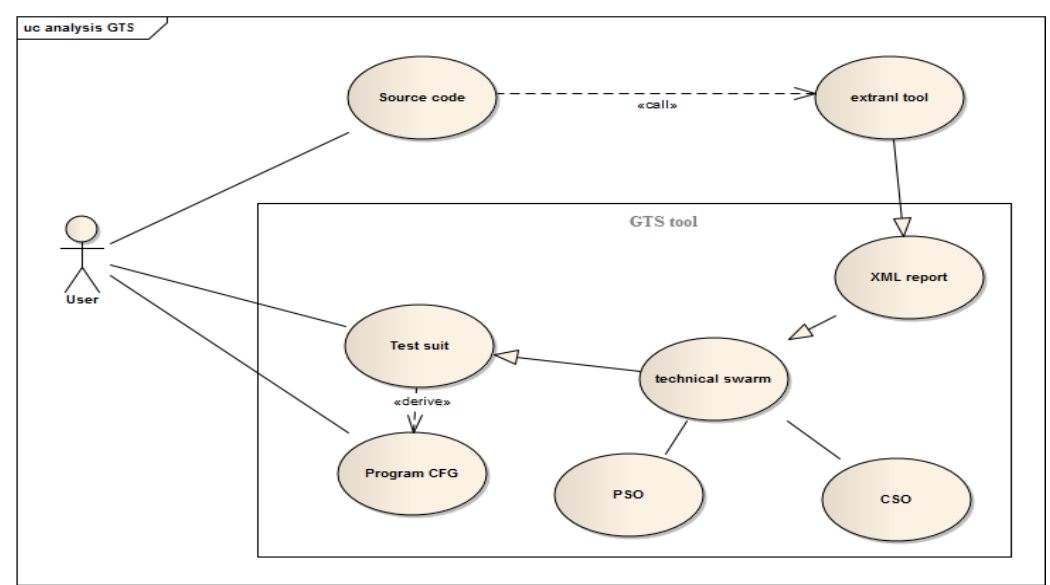

الثكل (11). تحليل الأداة من وجهة نظر المستخدم النهائي

إن أنموذج الأداة يستخلص المسارات للبرنامج المراد اختباره بلغه + C+ من تقرير بهيئة Xml وهو إخراج

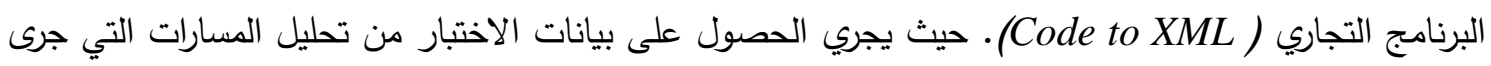

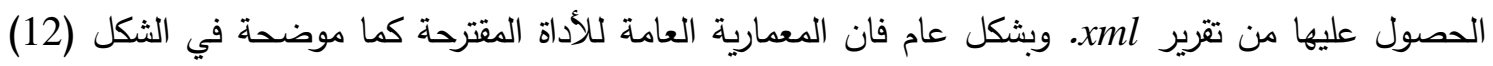
الذي يبين الأجزاء الرئيسة المكونة للأداة المقترحة.

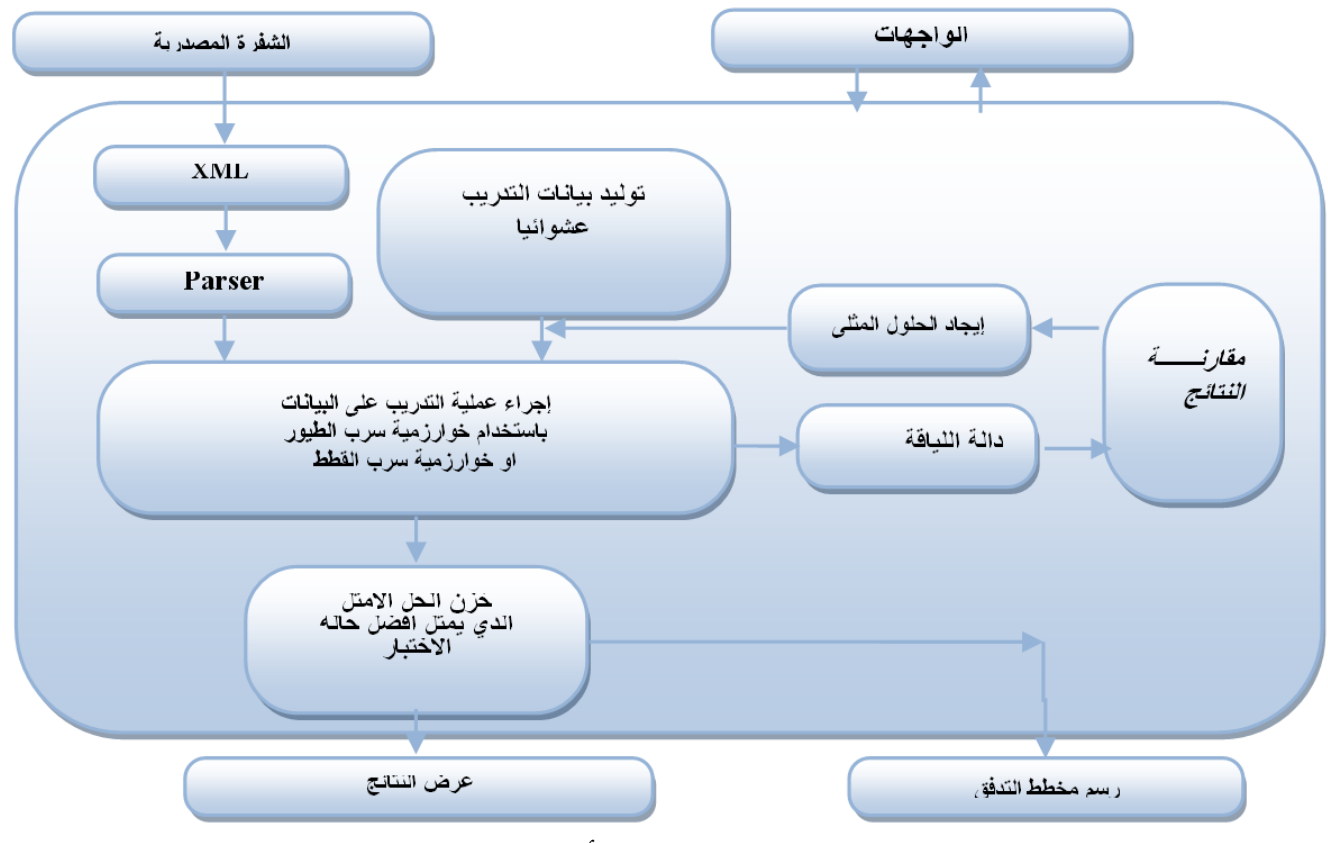

الثكل (12). معمارية الأداة المقترحة

11- النتائج

تتضمن هذه الفقرة كيفية التشثيل العملي Practical Implementation للأداة المقترحة بوصفها تتفيذاً للبرامج والنتائج التي جرى الحصول عليها فضلاً عن مناقثة هذه النتائج. وتعد هذه الفقرة استكمالاً لمرحلة بناء

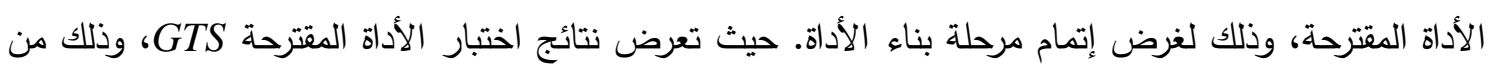

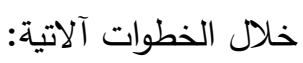
1. اختيار بيانات الاختبار المناسبة لمدخلات الأداة التي تتكون من ملف بصيغة XML يحوي على تحليل الثفرة

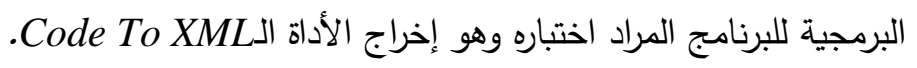


2. عرض نتائج توليد حالات الاختبار وتحليل الثفرة البرمجية من خلال توضيح المسارات ورسم مخطط تدفق

السيطرة للبرنامج المراد اختباره وذلك باستخدام إحدى التقنيات الذكائية الآتية:

$$
\text { • • ت توليد حالات الاختبار باستخدام خوارزمية سرب الطيور . }
$$

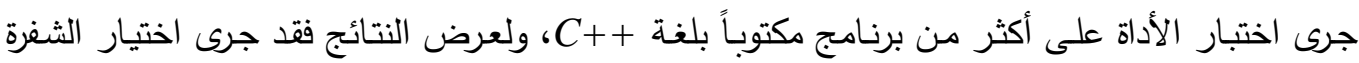
البرمجية المصدرية للبرنامج الأول المتضمن حالة IF وكما موضتح بالثكل (13). إذ حولت الشفرة البرمجية في الثكل السابق إلى صيغة الـ XML الموضحة في الثكل (14) وتعد هذه الصيغة إدخال للأداة المقترحة.

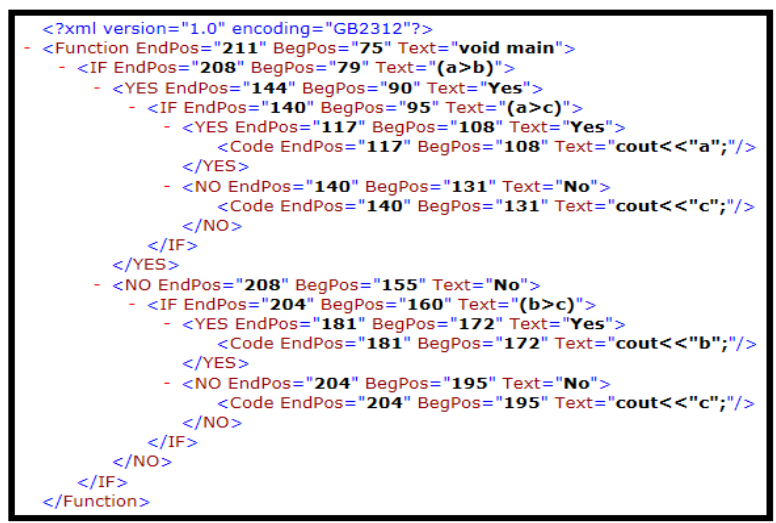

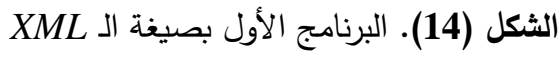

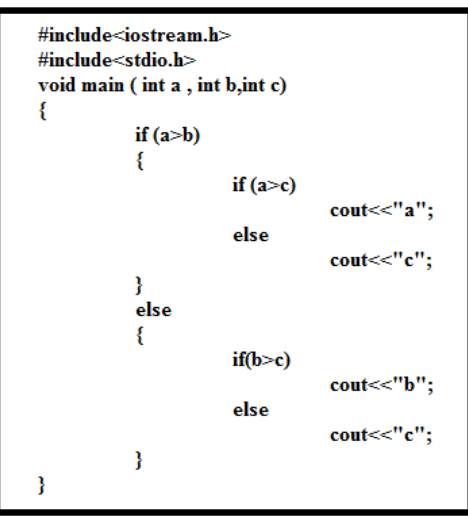

الثكل (13). الثفرة البرمجية المصدرية للبرنامج

الأول

• تتائج تنفيذ الأداة المقترحة باستخدام خوارزمية سرب الطيور الأبSO للبرنامج الأول

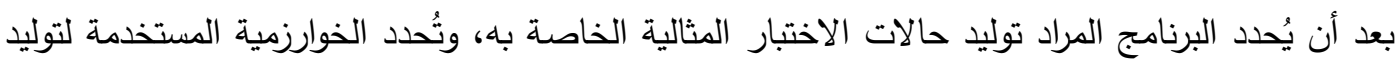

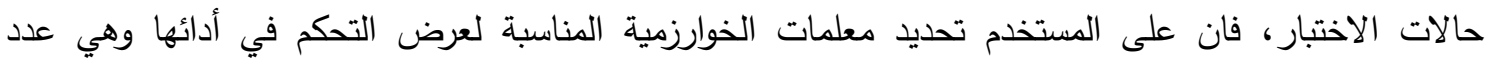
عناصر السرب وعدد التكرارات. وإن الأداة تدعم قيم افتراضية، في حالة عدم إدخال المستخدم لأية قيم جديدة. وقد

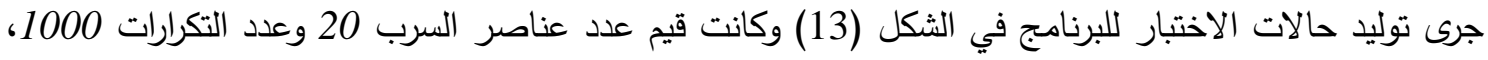
والثكل (15) يوضح واجهة منحني وصول خوارزمية PSO اللى الهدف.

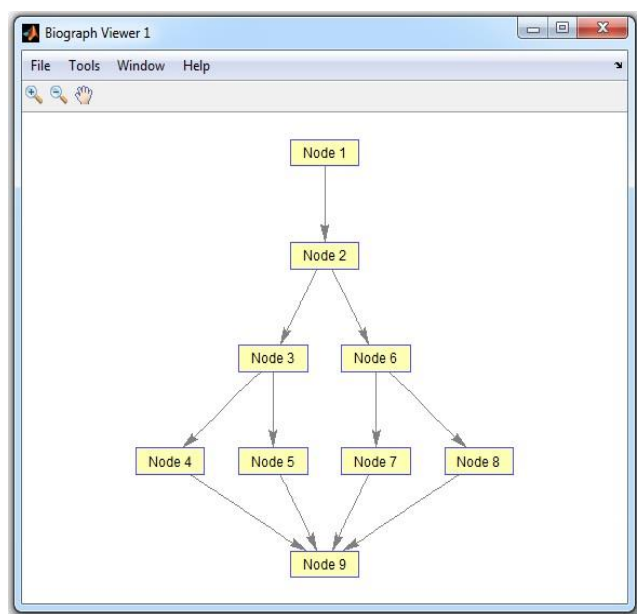

الثكل (16). مخطط التحكم في التدفق للبرنامج الأول

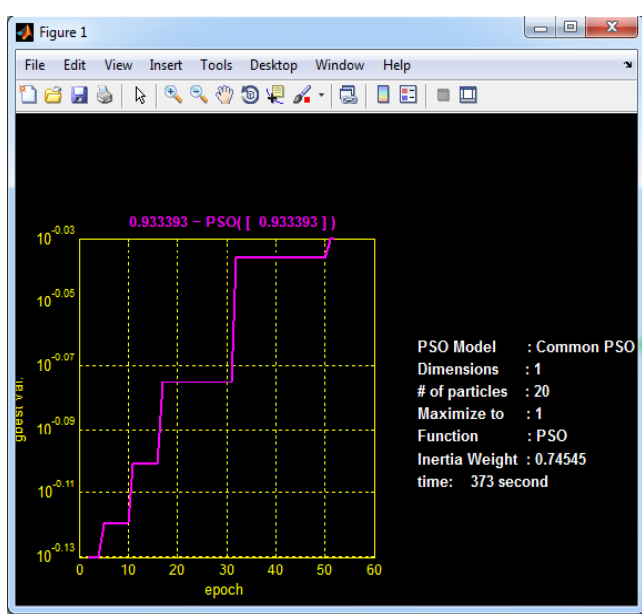

الثكل (15). منحني وصول خوارزمية POS إلى الهدف للبرنامج الأول 
وكانت نتائج التنفيذ كما يأتي: الوقت الذي استغرقته الأداة في الوصول إلى حالات الاختبار هو 373 ثانية، عدد التكرارات 52، نسبة الدقة 0.93، مخطط تدفق السيطرة للبرنامج كما موضح في الثكل (16)، حالات الاختبار

المثالية مع مسارات البرنامج الموضحة في الجدول (4).

الجدول (4). حالات الاختبار المثالية والمسارات الخاصة بها للبرنامج الأول باستخدام خوارزمية سرب الطيور

\begin{tabular}{|c|c|}
\hline حالات الاختبار المولدة & الطريق المتبع لحالات الاختبار المولدة \\
\hline$\{-15677,-16231,-16073\}$ & $\{1-2-3-4-9\}$ \\
\hline$\{10523,11854,11034\}$ & $\{1-2-6-7-9\}$ \\
\hline$\{32767,32767,32767\}$ & $\{1-2-6-8-9\}$ \\
\hline$\{32758,31692,32767\}$ & $\{1-2-3-5-9\}$ \\
\hline
\end{tabular}

• • نتائج تنفيذ الأداة المقترحة باستخدام خوارزمية سرب القطط CSO للبرنامج الأول

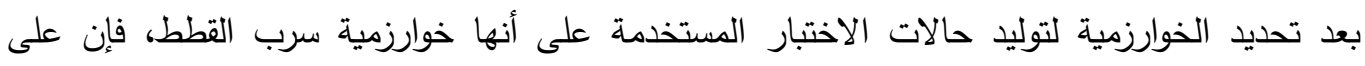

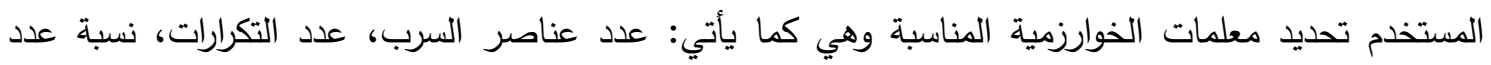

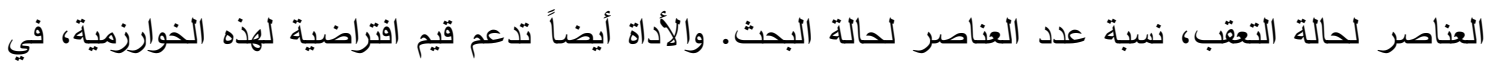
حالة عدم إدخال المستخدم لأي قيم جديدة. وقد جرى توليد حالات اختبار للبرنامج في الشكل (13) وكانت قيم

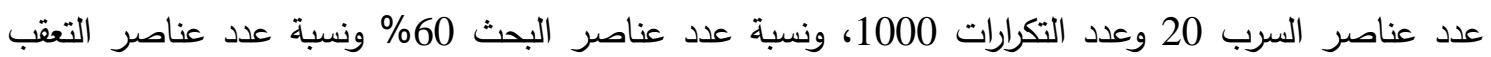
40 والثكل(17) يوضح منحني وصول خوارزمية CSO إلى الهدف.

الجدول (5). حالات الاختبار المثالية والمسارات الخاصة

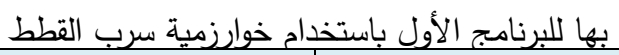

\begin{tabular}{|c|c|}
\hline حالات الاختبار المولدة & الطريق المتبع للحالات \\
\hline$\{-8,43,64\}$ & $\{1-2-6-8-9\}$ \\
\hline$\{108,-56,-12\}$ & $\{1-2-3-4-9\}$ \\
\hline$\{74,-17,106\}$ & $\{1-2-3-5-9\}$ \\
\hline$\{-139,142,75\}$ & $\{1-2-6-7-9\}$ \\
\hline
\end{tabular}

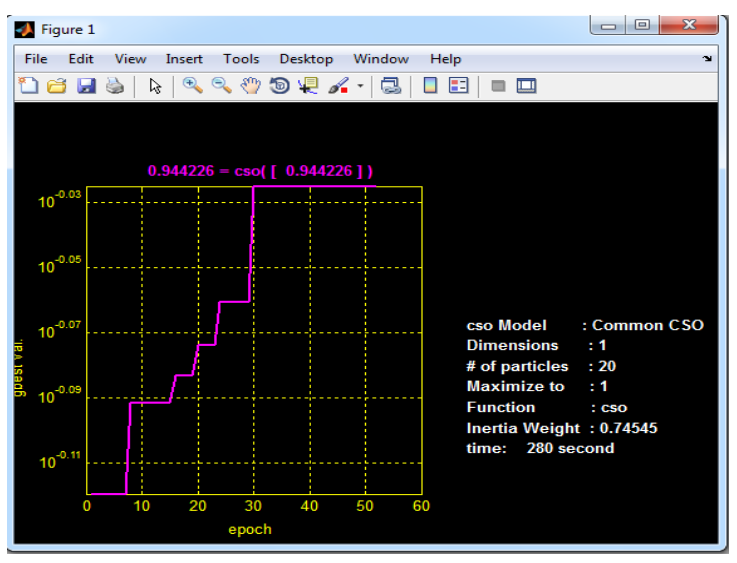

الثكل (17). منحني وصول خوارزمية COS إلى الهدف للبرنامج الأول

وكانت نتائج التنفيذ كما يأتي: الوقت الذي استغرقته الأداة في الوصل إلى حالات الاختبار هو 280 ثانية، عدد التكرارات 52، نسبة الدقة 0.94، مخطط تدفق السيطرة للبرنامج كما موضح في الشكل (16). وحالات الاختبار المثالية مع مسارات البرنامج موضحة في الجدول (5).

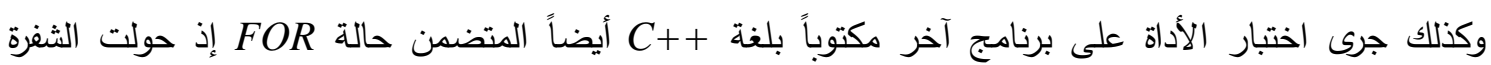
البرمجية إلى صيغة الـ XML وتعد هذه الصيغة إدخال للأداة المقترحة.

• نتائج تنفيذ الأداة المقترحة باستخدام خوارزمية سرب الطيورPSO للبرنامج الثاني 


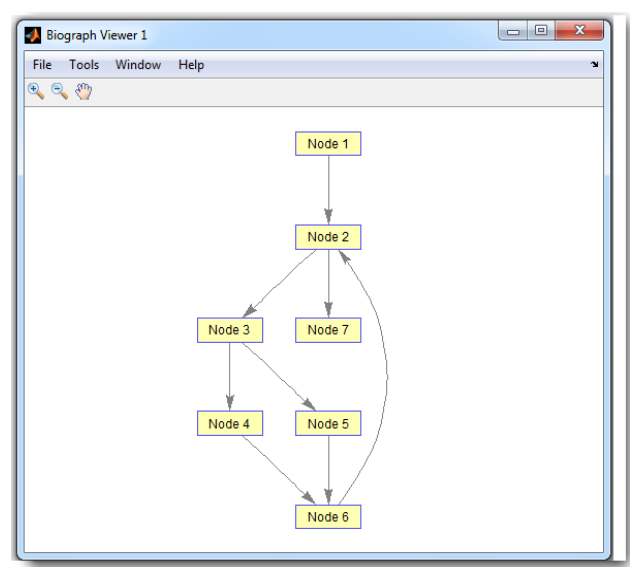

الثكل (19). مخطط التحكم في التدفق للبرنامج الثاني

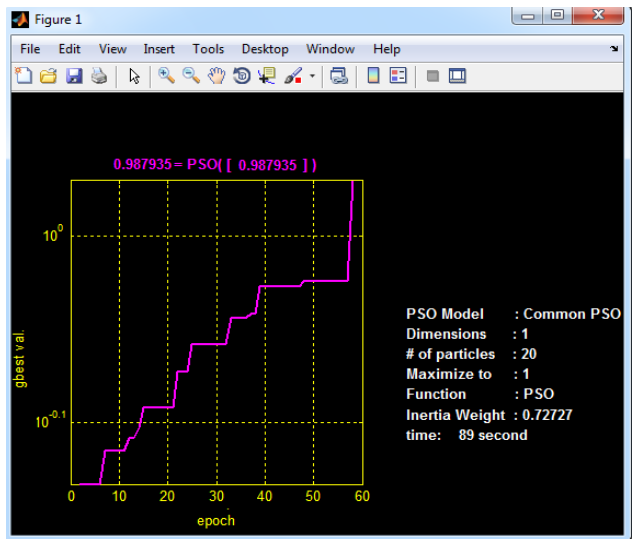

الثكل (18). منحني وصول خوارزمية POS إلى

$$
\text { الهاف للبرنامج الثاني }
$$

وكانت نتائج التتفيذ كما يأتي: الوقت الذي استغرقته الأداة في الوصول إلى حالات الاختبار هو 89 ثانية، عدد تكرارات 58، نسبة الدقة 0.98، مخطط تدفق السيطرة للبرنامج كما موضح في الثكل (19). حالات الاختبار

المثالية مع المسارات البرنامج الموضحة في الجدول (7).

الجدول (7). حالات الاختبار المثالية والمسارات الخاصة بها للبرنامج الثاني باستخدام خوارزمية سرب الطيور

\begin{tabular}{|c|c|}
\hline حالات الاختبار المولدة & الطريق المتبع للحالات الاختبار المولدة \\
\hline$\{2,3\}$ & $\{1-2-3-4-6-2-7\}$ \\
\hline$\{5,1\}$ & $\{1-2-3-5-6-2-7\}$ \\
\hline$\{6,11\}$ & $\{1-2-7\}$ \\
\hline
\end{tabular}

• نتائج تنفيذ الأداة المقترحة باستخدام خوارزمية سرب القطط CSO للبرنامج الثاني الجدول (8). حالات الاختبار المثالية والمسارات

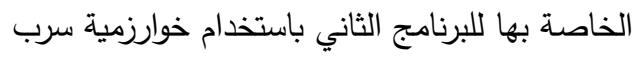
القطط

\begin{tabular}{|c|c|}
\hline $\begin{array}{c}\text { الطريق المتبع لحالات } \\
\text { الاختبار المولدة الاختارة }\end{array}$ \\
\hline$\{3,5\}$ & $\{1-2-7\}$ \\
\hline$\{2,3\}$ & $\{1-2-3-4-6-2-7\}$ \\
\hline$\{4,0\}$ & $\{1-2-3-5-6-2-7\}$ \\
\hline
\end{tabular}

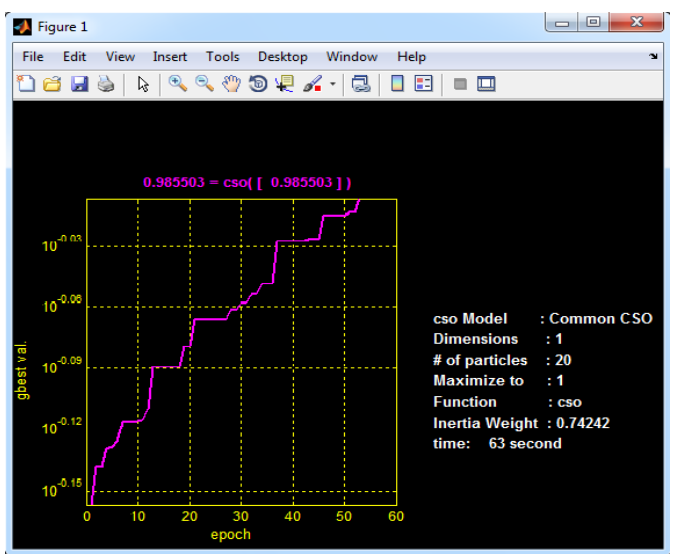

الثكل (20). منحني وصول خوارزمية COS إلى الهدف

$$
\text { كلبرنامج الثاني }
$$

وكانت نتائج التنفيذ كما يأتي: الوقت الذي استغرقته الأداة في الوصول إلى حالات الاختبار هو 63 ثانية، عدد التكرارات 53، نسبة الدقة 0.98، مخطط تدفق السيطرة للبرنامج كما موضح في الشكل (19)، حالات الاختبار المثالية مع مسارات البرنامج الموضحة في الجدول (8).

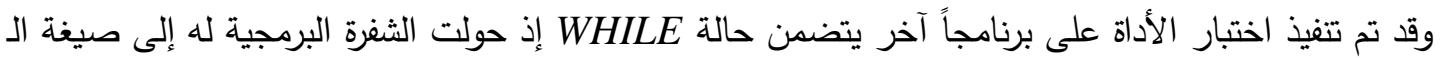
XML وهذه الصيغة تعد إدخال للأداة المقترحة. 
• • نتائج تنفيذ الأداة المقترحة باستخام خوارزمية سرب الطيورPSO للبرنامج الثالث

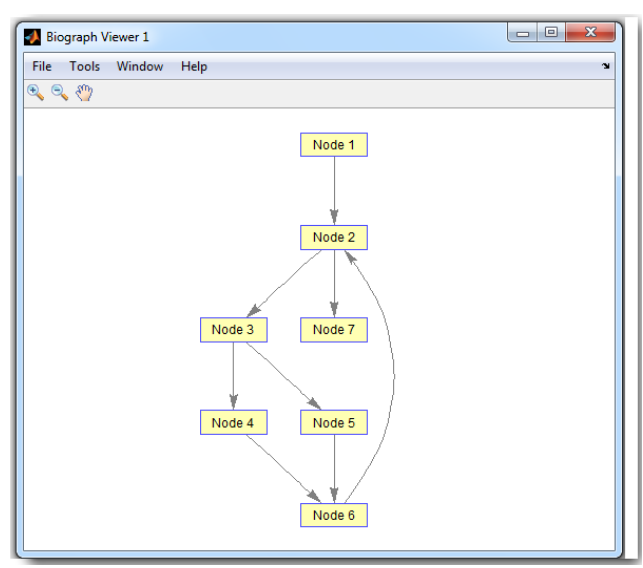

الشكل (22). مخطط التحكم في التذفق للبرنامج الثالث

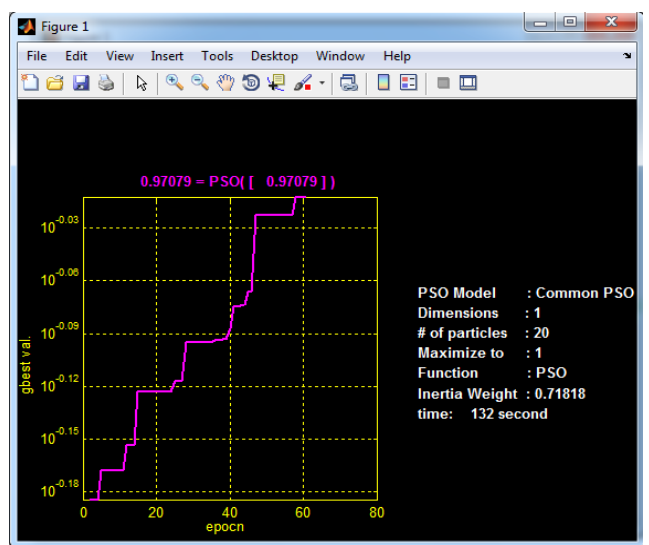

الثكل (21). منحني وصل خوارزمية POS إلى الهدف

$$
\text { للبرنامج الثالث }
$$

وكانت نتائج التتفيذ كما يأتي: الوقت الذي استغرقته الأداة في الوصول إلى حالات الاختبار هو 132 ثانية، عدد التكرارات 61، نسبة الدقة 0.97، مخطط تدفق السيطرة للبرنامج كما موضح في الثكل (22)، حالات الاختبار المثالية مع مسارات البرنامج الموضحة في الجدول (9). الجدول (9). حالات الاختبار المثالية والمسارات الخاصة بها للبرنامج الثالث باستخدام خوارزمية سرب الطيور

\begin{tabular}{|c|c|}
\hline الطريق المتبع للحالات الاختبار المولدة & الات الاختبار المولدة \\
\hline$\{8,59\}$ & $\{1-2-3-4-6-2-7\}$ \\
\hline$\{13,30\}$ & $\{1-2-3-5-6-2-7\}$ \\
\hline$\{88,9\}$ & $\{1-2-7\}$ \\
\hline
\end{tabular}

• تائج تتفيذ الأداة المقترحة باستخدام خوارزمية سرب القطط CSO للبرنامج الثالث الجدول (10). حالات الاختبار المثالية والمسارات

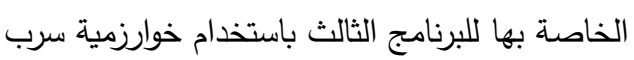

\begin{tabular}{|c|c|}
\hline $\begin{array}{c}\text { الطريت المتبع للحالات الاختبار المولدة } \\
\text { الاختبار المولدة }\end{array}$ \\
\hline$\{22,71\}$ & $\{1-2-3-4-6-2-7\}$ \\
\hline$\{19,40\}$ & $\{1-2-3-5-6-2-7\}$ \\
\hline$\{31,8\}$ & $\{1-2-7\}$ \\
\hline
\end{tabular}

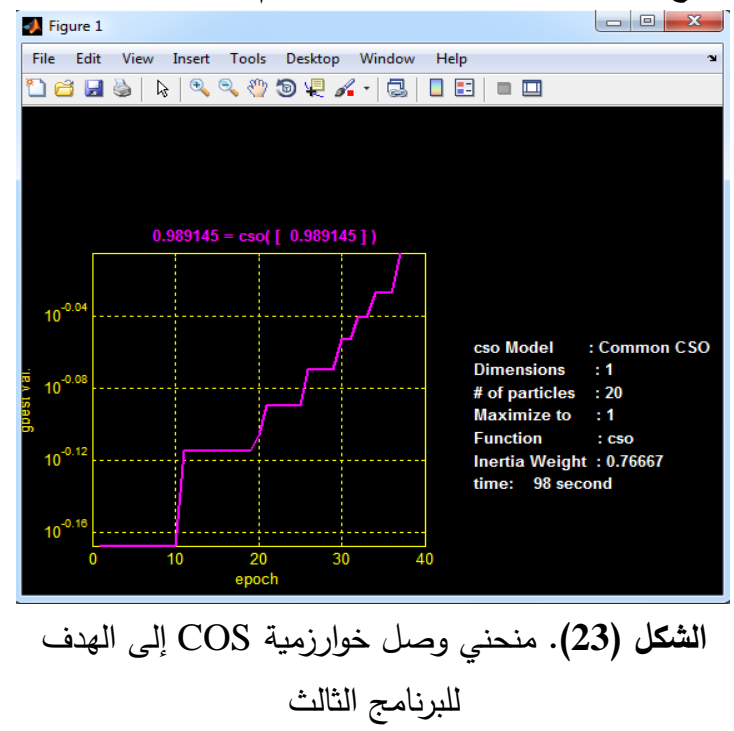

وكانت نتائج التنفيذ كما يأتي: الوقت الذي استغرقته الأداة في الوصل إلى حالات الاختبار هو 98 ثانية. عدد التكرارات 45 ونسبة الدقة 0.99. مخطط تدفق السيطرة للبرنامج موضتح في الثكل (22). حالات الاختبار المثالية مع المسارات البرنامج موضحة في الجدول (10). 12- مقارنة نتائج الخوارميتان في توليا حالات الاختبار 
لغرض بناء مقارنة دقيقة بين الخوارزميتان، فقد جرى فحص أداء الأداة المقترحة على ثلاثة برامج مختلفة، البرنامج الأول المتضمن حالة if والثاني المتضمن حالة for والثالث حالة while. الجدول رقم (11) يبين نتائج توليد حالات الاختبار للبرامج الثلاثة من ناحية السرعة والدقة والأداء. الجدول (11). نتائج توليد حالات الاختبار للبرامج الثلاثة من ناحية السرعة والدقة والأداء باستخدام خوارزمية سرب الطيور وخوارزمية سرب القطط

\begin{tabular}{|c|c|c|c|c|c|c|}
\hline \multicolumn{3}{|c|}{ خوارزمية سرب القطط } & \multicolumn{3}{|c|}{ خوارزمية سرب الطيور } & الذاصية \\
\hline$P 3$ & $P 2$ & $P 1$ & $P 3$ & $P 2$ & $P 1$ & اسم البرنامج \\
\hline 98 & 63 & 280 & 132 & 89 & 373 & الوقت المستغرق \\
\hline 45 & 53 & 52 & 61 & 58 & 52 & التكرارات \\
\hline 0.99 & 0.98 & 0.94 & 0.97 & 0.98 & 0.93 & الاقة \\
\hline
\end{tabular}

كما يتضح من الجدول أعلاه إن توليد حالات الاختبار باستخدام خوارزمية سرب القطط كانت الأفضل لجميع البرامج المختارة في البحث اعتماداً على المقاييس المحسوبة. 13- الاستنتاجات

من خلال بناء أداة لتوليد حالات الاختبار GTS tool التي صممت في هذا البحث والتي تتضمن توليد

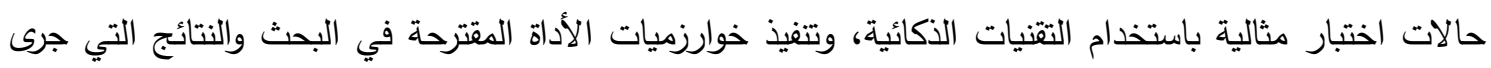
الحصول عليها من التتفيذ العملي للأداة المقترحة، استحصلت استتناجات عديدة تتلخص كما يأتي: • استتنج أن توليد حالات الاختبار بشكل تلقائي يوفر لفريق تطوير البرمجيات مزايا عديدة: يقلل من الوقت المستغرق لتوليد حالات اختبار مثالية لفحص البرمجيات.

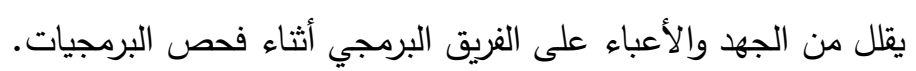

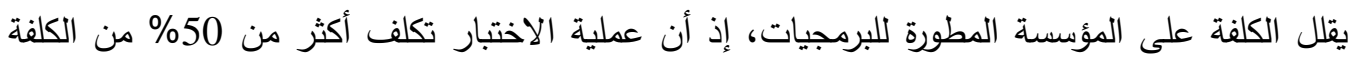
الكلية لتطوير البرمجيات. استخدام الأداة المقترحة GTS في توليد حالات الاختبار بشكل تلقائي ساعد في تقليل عدد من مشكلات توليد حالات الاختبار بشكل يدوي. هُ ان استخدام التقنيات الذكائية لمساعدة هندسة البرمجيات يعطي دفعة قوية وسرعة ودقة متتاهيتين في دعم مراحل هندسة البرمجيات ولاسيما في مرحلة فحص البرمجيات.

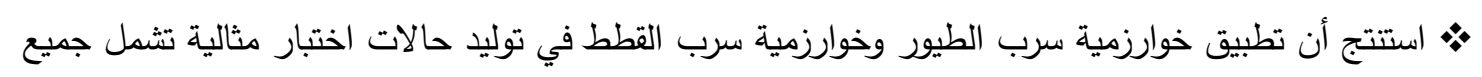

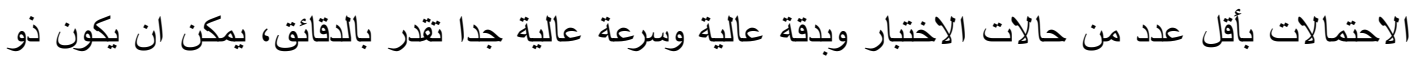
فائدة كبير في هندسة البرمجيات. • إن استخدام خوارزمية سرب الطيور في توليد حالات الاختبار ومن خلال التطبيق العملي على عدة برامج

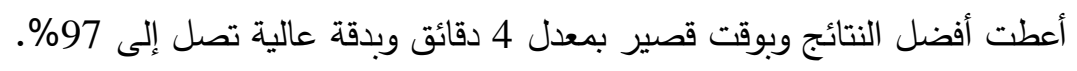


• يتبين عند استخدام خوارزمية سرب القطط في توليد حالات الاختبار ومن خلال التطبيق العملي على عدة

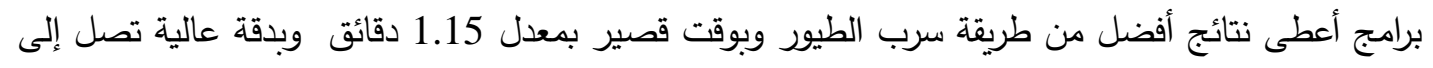
\%99 • وأخيرا لوحظ من خلال المقارنة التي أجريت بين خوارزمية سرب الطيور وخوارزمية سرب القطط في الجدول (11)، أن خوارزمية سرب القطط كانت أفضل من ناحية السرعة والدقة في الوصول إلى حالات الاختبار

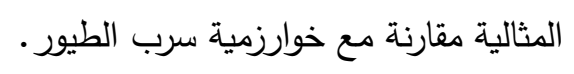




$$
\text { زاهر الحاج حسين، 2006، "هندسة البرمجيات ثنائية الهندسة والإدارة"، شعاع للنشر والعلوم. }
$$

[2] Sangeeta Sabharwal, Ritu Sibal, Chayanika Sharma, 2011, "A Genetic Algorithm based approach for prioritization of test case scenarios in static testing", IEEE, International Conference on Computer \& Communication Technology (ICCCT).

[3] Ioan Mihnea, Radu, 2008, "Testing: First Step Towards Software Quality", journal of applied Quantitative Methods.

[4] Mohd. Ehmer Khan, 2010, "Different Forms of Software Testing Techniques for Finding Errors", IJCSI International Journal of Computer Science Issues.

[5] Mohd. Ehmer Khan. 2011, "Different Approaches to White Box Testing Technique for Finding Errors", International Journal of Software Engineering and Its Applications.

[6] Sowmya Padmanabhan, 2004, "Domain Testing: Divide and Conquer", Master Thesis, in Computer Sciences, Florida Institute of Technology, Melbourne, Florida

[7] Gustaf Brannstrom, 2012, "Automated software testing for cross-platform systems", Master's Thesis in Computing Science, Umea University Department of Computing Science, SWEDEN.

[8] Naveen Jayachandran, 2005,"Understanding ROI Metrics for Software Test Automation", Master thesis, in Computer Science Department of Computer Science and Engineering College of Engineering, University of South Florida

[9] Harmen - Hinrich Sthamer, 1995, "The Automatic Generation of Software Test Data Using Genetic Algorithms", Doctor of Philosophy thesis, University of Glamorgan / Prifvsgol Morgannwg.

[10] Pankaj Jalote, 2008, "A Concise Introduction to Software Engineering", Springer, Science+Business Media.

[11] Ranjita Swain, Vikas Panthi, Prafulla Kumar Behera, Durga Prasad Mohapatra, 2012, "Automatic Test case Generation From UML State Chart Diagram", International Journal of Computer Applications.

[12] Chen Mingsong, Qiu Xiaokang, Li Xuandong, 2006, "Automatic Test Case Generation for UML Activity Diagrams", ACM, Shanghai, China.

[13] Xiaohui Cui, Thomas E. Potok, 2006, "Swarm Intelligence in Text Document Clustering", Computational Sciences and Engineering Division Oak Ridge National Laboratory.

[14] Dr.R.Umarani, V.Selvi, 2010, "Particle Swarm Optimization-Evolution, Overview and Applications", International Journal of Engineering Science and Technology.

[15] Sanjay Singla, Dharminder Kumar, H M Rai, Priti Singla, 2011,"A Hybrid PSO Approach to Automate Test Data Generation for Data Flow Coverage with 
Dominance Concepts", International Journal of Advanced Science and Technology.

[16] Ajith Abraham, Crina Grosan, Vitorino Ramos, 2006, "Swarm Intelligence in Data Mining", Springer-Verlag Berlin Heidelberg.

[17] Noel D. Bacarisas, John Paul T. Yusiong, 2011, The Effect of Varying the Fitness Function on the Efficiency of the Cat Swarm Optimization algorithm in Solving the Graph Coloring Problem", Annals, Computer Science Series.

[18] Budi Santosa, Mirsa Kencana Ningrum, 2009, "Cat Swarm Optimization for Clustering", IEEE, International Conference of Soft Computing and Pattern Recognition.

[19] Maysam Orouskhani, Mohammad Mansouri, Mohammad Teshnehlab, 2011, "Average-Inertia Weighted Cat Swarm Optimization", Springer-Verlag Berlin Heidelberg.

[20] Pyari Mohan Pradhan, Ganapati Panda, 2012, " Solving multiobjective problems using cat swarm optimization", Elsevier Ltd. Expert Systems with Applications 2956-2964.

[21] Jong-Ching Hwang, Jung-Chin Chen, J.S. Pan, Yi-Chao Huang, 2009, "CSO and PSO to Solve Optimal Contract Capacity for High Tension Customers", Electrical Engineering Department, National Kaohsiung University of Applied Sciences, Kaohsiung, Taiwan.

[22] Ganapati Panda, "Cat Swarm Optimization: Theory and Application to Direct and Inverse Modeling", School of Electrical Sciences, Indian Institute of Technology Bhubaneswar.

[23] Harsimran Singh, 2004, "Automatic Generation of Software Test Cases using Genetic Algorithms", Master thesis In Software Engineering, Computer Science \& Engineering Department Thapar Institute of Engineering \& Technology, Patiala.

[24] Bogdan Korel, 1990, "Software Test Data Generation", IEEE, Computer Sociaty and Association for Computing Machinery. 